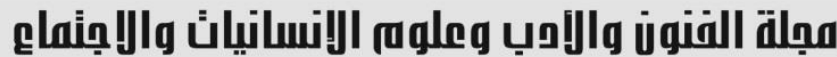

Journal of Arts, Literature, Humanities and Social Sciences www.jalhss.com

\section{برنامج تدريبي مقترح كمدخل للمشاريع الصغيرة لتتمية مهارات الأرامل بالمجتمع السعودي (دراسة استطلاعية)}

حمده عايد صياح الرويلي

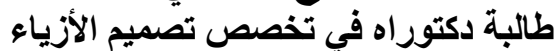

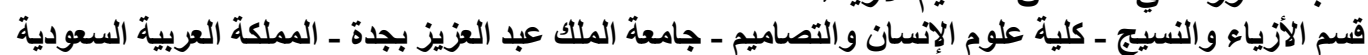
الايميل: Mh2432004@gmail.com

أ.د. نيرمين عبد الرحمن عبد الباسط قسم الأزياء و النسيج - كلية علوم الإنسان والتصاميم - جامعة الملك عبد العزيز بجدة ـ المملكة العربية السعودية

التدريب أداة التنمية ووسيلتها التي إذا أحسن استثمار ها تمكن من تحقيق الكفاءة في الأداء ، فهو نشاط مخطط

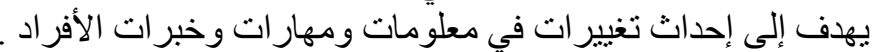

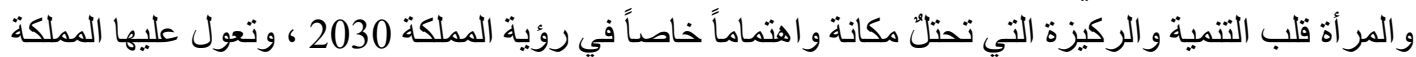

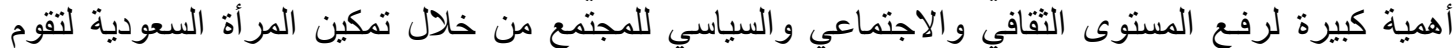

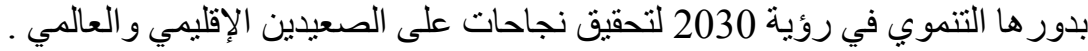
و المشاريع الصغيرة تخلق فرص للعمل وتحرك قاطرة الصناعة نحو مستقبلاً واعداً لذوب الدخل المحدود الطيا

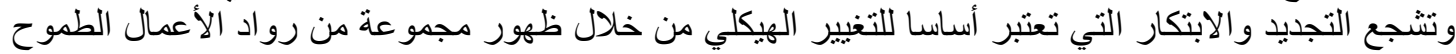
ذوي الكفاءة و النشاط.

$$
\text { هدف البحث إلى : }
$$
1- تصميم برنامج تدريبي مقتر ح لتنمية المهار ات الفنية للأر امل بالمجتمع السعودي. 2- قياس فاعلية البرنامج التدريبي المقترح لتنمية المهار ات الفنية للأر امل بالمجتمع السعودي في مدينة الخبر.

1- تبادل الخبرات المكتسبة بين المختصين في المجال و التخصصات الأخرى للنطوير ودمجها في التطبيق

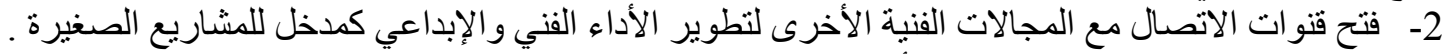

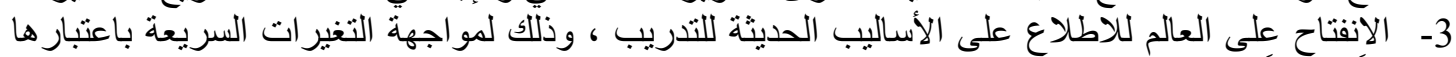

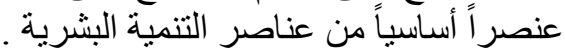
4- التأكبد على دور الجامعات لحثهم على إجر اء الأبحاث و الدراسات عن مؤسسات الدولة . الكلمات المفتاحية: برنامج تدريبي، المشاريع الصغيرة، مهار ات الأرامل، المجتمع السعودي. 


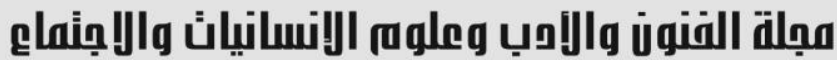 \\ Journal of Arts, Literature, Humanities and Social Sciences \\ www.jalhss.com
}

Volume (60) November 2020

العدد (60) نوفمبر 2020 - | (60)

\section{A proposed Training Program as an Entry Point for Small Projects to Develop Widows' Skills in Saudi Society (An exploratory study)}

\author{
Hamda Ayed Sayah Al-Ruwaili \\ A PhD student in Fashion Design \\ Department of Fashion and Textile - College of Human Sciences and Design - King \\ Abdulaziz University in Jeddah - Kingdom of Saudi Arabia \\ Email: Mh2432004@gmail.com
}

Prof. Dr. Nermin Abdel-Rahman Abdel-Basit

Department of Fashion and Textile - College of Human Sciences and Design - King Abdulaziz University in Jeddah - Kingdom of Saudi Arabia

\section{ABSTRACT}

Training is a development tool and means that, if properly invested, enables the achievement of efficiency in performance. It is a planned activity aimed at bringing about changes in the information, skills, and experiences of individuals. Women are the heart of development and the pillar that occupies a special position and interest in the Kingdom's Vision 2030, and the Kingdom relies on it great importance to raise the cultural, social and political level of society by empowering Saudi women to play their development role in Vision 2030 to achieve successes at the regional and global levels. Small enterprises create job opportunities and move the industry towards a promising future for low-income people and encourage innovation and innovation, which are the basis for structural change through the emergence of a group of ambitious, efficient and dynamic entrepreneurs.

Research goal to:

1- Designing a proposed training program to develop the technical skills of widows in the Saudi society.

2- Measuring the effectiveness of the proposed training program to develop the technical skills of widows in the Saudi society in Khobar.

I recommend searching:

1- Exchanging the acquired experiences between specialists in the field and other disciplines of development and integrating them into the application to raise the technical and skill level.

2- Opening communication channels with other technical fields to develop artistic and creative performance as an entry point for small projects.

3- Openness to the world to learn about modern methods of training, in order to face rapid changes as an essential element of human development.

4- Emphasizing the role of universities to urge them to conduct research and studies on state institutions.

Keywords: training program, small projects, Widows Skills, Saudi Society. 


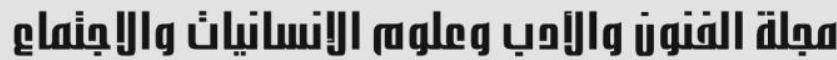

Journal of Arts, Literature, Humanities and Social Sciences

www.jalhss.com

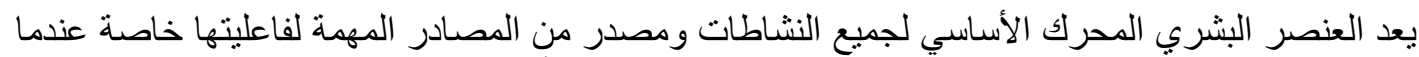
يتميز بنو عية مهارية ومعرفية وقدرات وقابليات تتلاعم مع طبيعة الأعمال التي يمارسها (الطعاني ، حسن ،

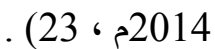

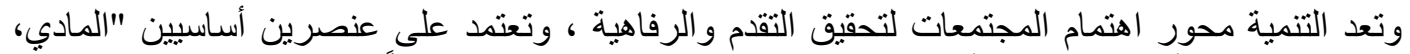

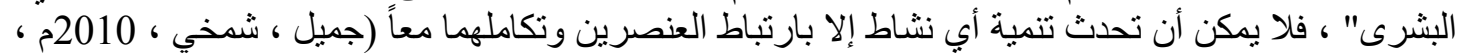

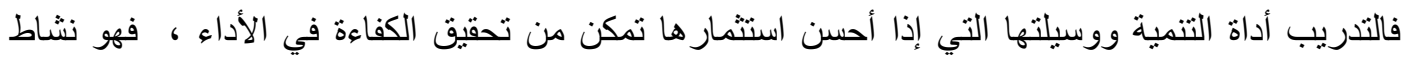
مخطط يهدف إلى إحداث تغيير ات في معلومات ومهار ات وخبرات الأفراد (جميل ، عبدالكريم ، 2016م ، ، 4.

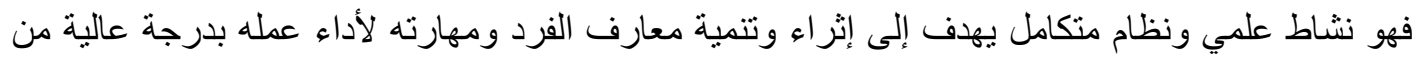

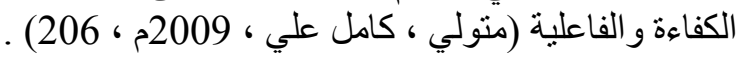

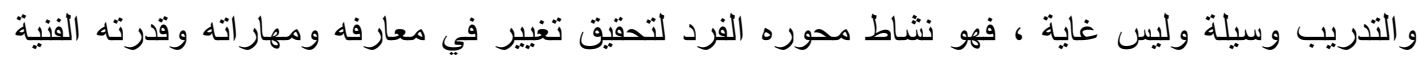
المقابلة لاحتياجات محددة في ضوء منطلبات العمل وتطلعاته المستقبلية لدوره في المجتمع (محمد ، صلاح فئه الدين

. (13 ، 2011،

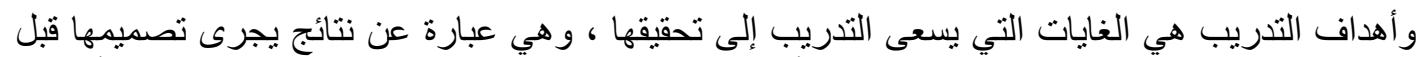

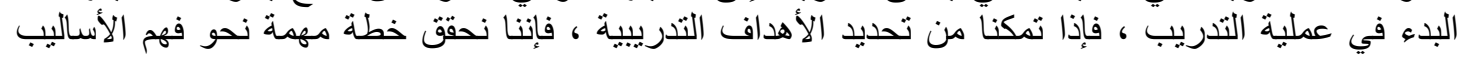

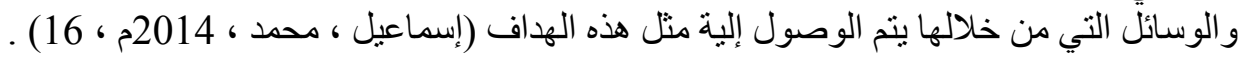

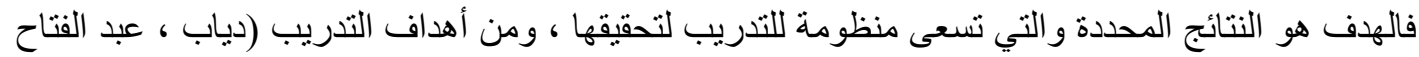

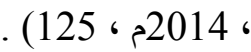

وتسعي البر امج التدريبية لتحقيق مفهوم جديد يتلاءم مع الانفجار المعرفي و الثورة العلمية و التقنية التي نعيشها

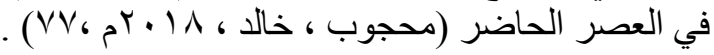

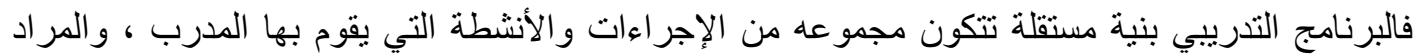

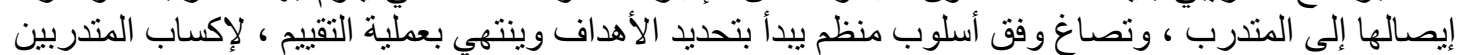

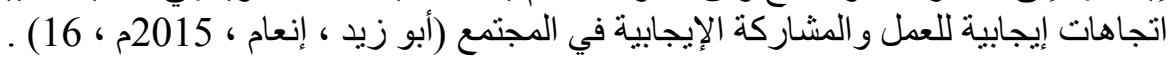

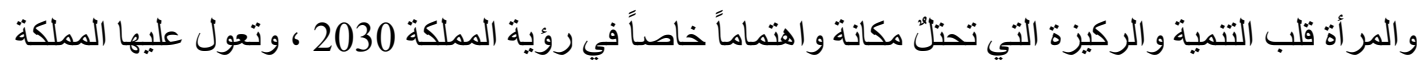

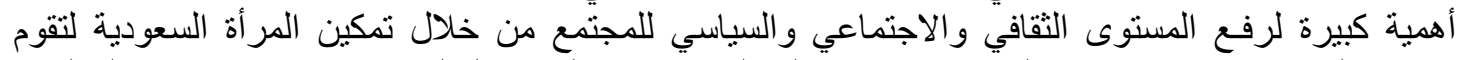

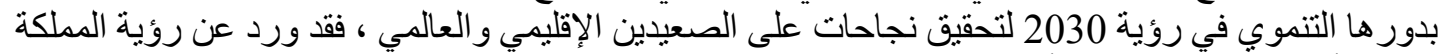

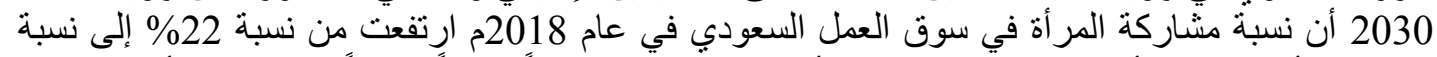

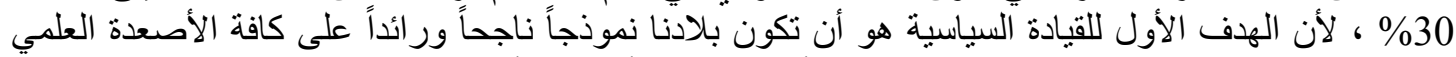

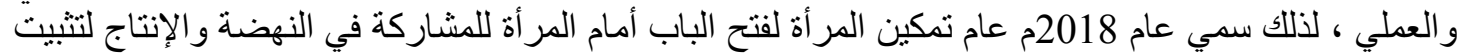

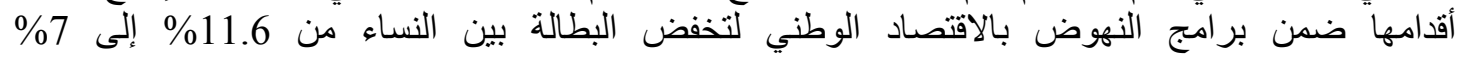
.https://www.stats.gov.sa وقد أثنار (Alasrag , 2010) أن المشاريع الصغيرة تخلق فرص للعمل وتحرك قاطرة الصناعة نحو

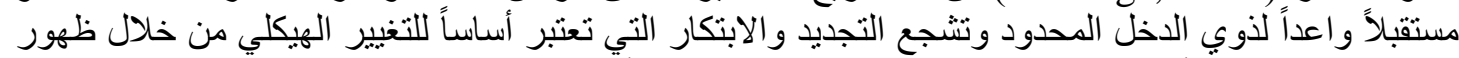

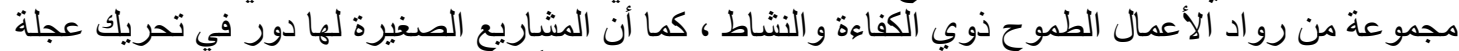

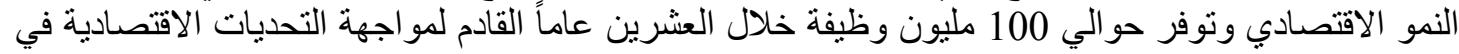

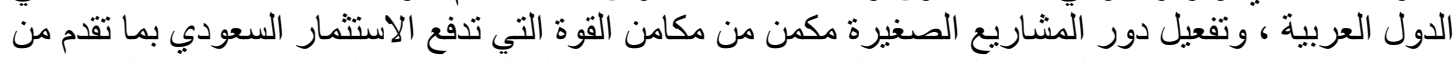

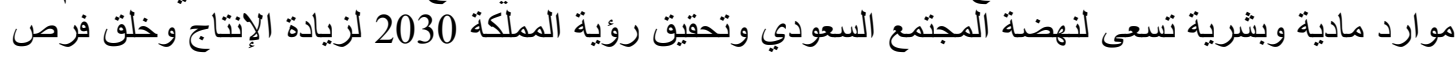

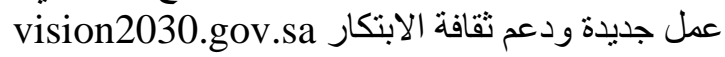

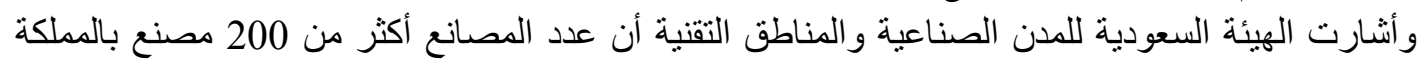

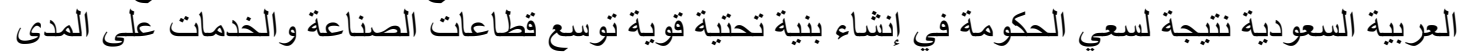
الطويل لتمكن الاقتصاد السعودي من المحافظة على قوته خلاءل السنة السنو ات القادمة. 


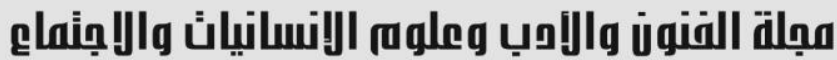

Journal of Arts, Literature, Humanities and Social Sciences www.jalhss.com

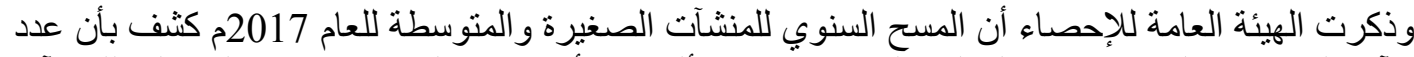

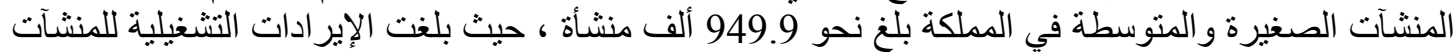

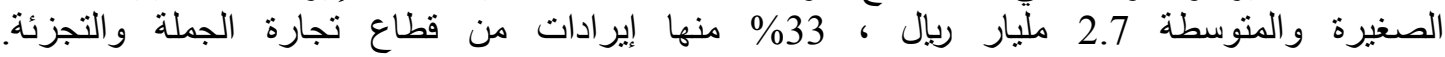
www.stats.gov.sa

كما تطرقت الهيئة العامة للإحصاء السعودية أن عدد الأرامل من النساء في المملكة بلغ حتى نهاية العام

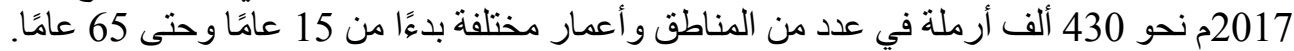
www.vision2030.gov.sa

و الأرمل شريحة من شر ائح النساء السعوديات التي يحتجن وقتاً للتكيف مع وضعهن الاجتماعي و الاقتصادي

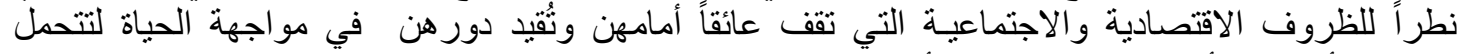

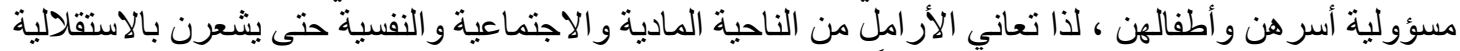

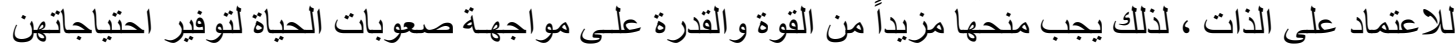

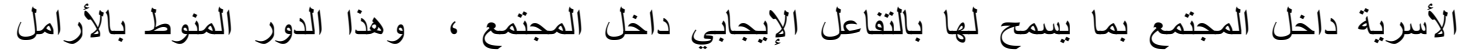

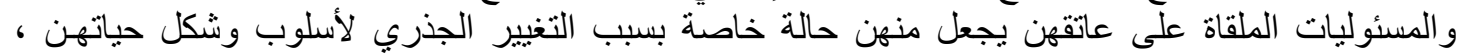

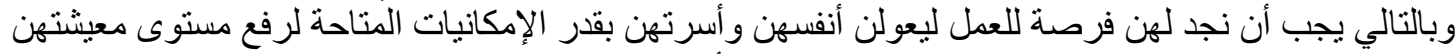

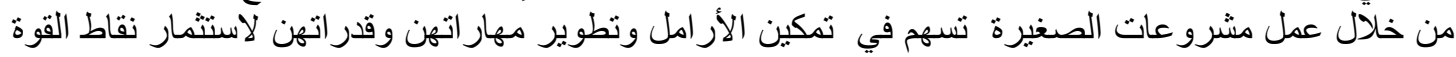

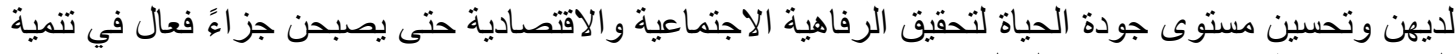
الحيوي عن طريق غرس ثقافة العمل و الإنتاج. Www.mlsd.gov.sa

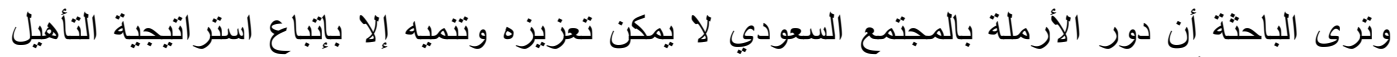

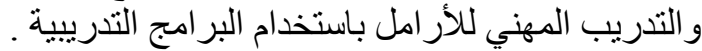

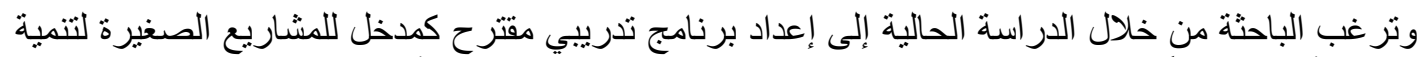

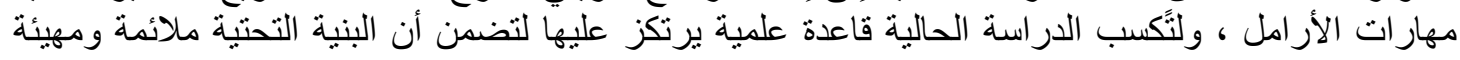

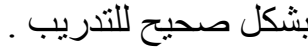

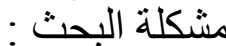

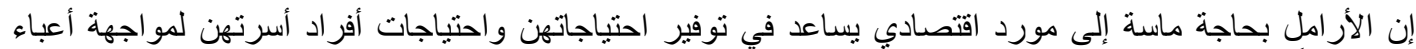

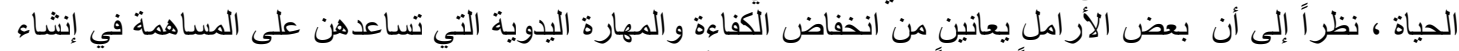

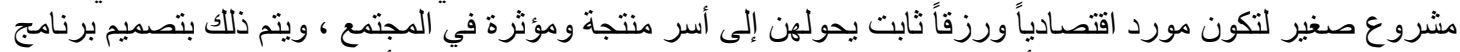

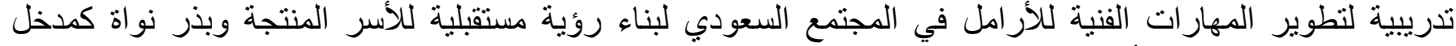

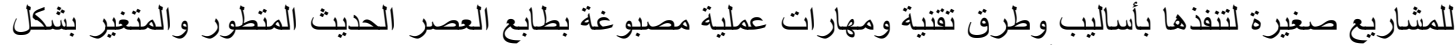

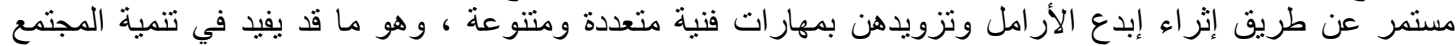

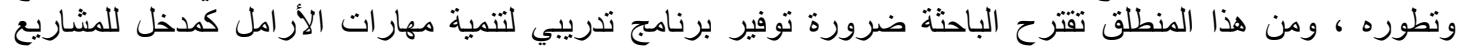

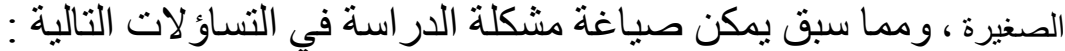

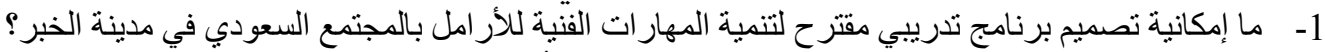

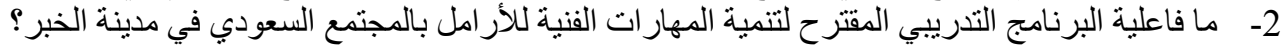

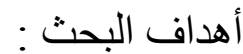
1- تصميم برنامج تدريبي مقتر ح لتتمية المهار ات الفنية للأر امل بالمجتمع السعودي.

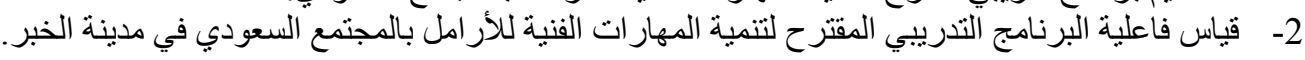

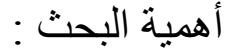

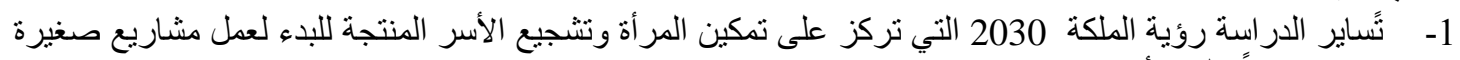
يعود ريعها إيجابياً على الأسرة .

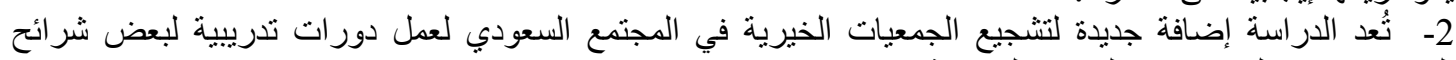

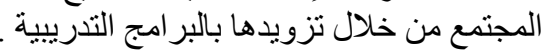
3- تساهم الدراسة في التنمية الاجتماعية والأسرية لثريحة من المجتمع السعودي عن طريق تتمية القدرات الفنية

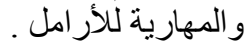
4- خلق فرص عمل للأرامل وللأسر المنتجة من خلال تثنجيع المشاريع الصغيرة التي بدورها تدعم اقتصاد الأسرة وبالتالي يسهم في إيجاد حلول لبعض المشكلات الاقتصادية. 


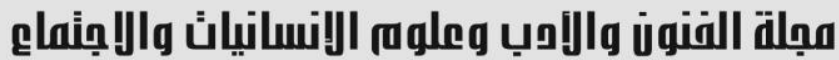

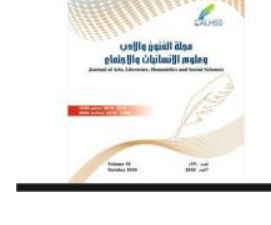

Journal of Arts, Literature, Humanities and Social Sciences

www.jalhss.com

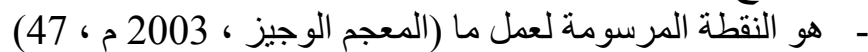

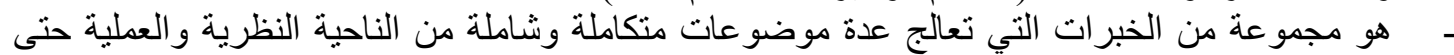

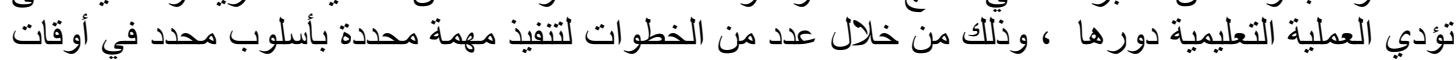

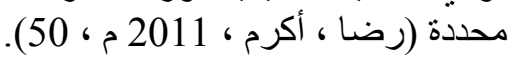

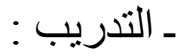
- في اللغة العربية بعني التعويد و التأديب و المران ، فيقال درب الفرس أي أدبه و علمه ومرنه (عبد اللطيف ،

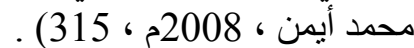
- عملية منظمة تهدف إلى أحداث تغير ات فنبة لمقابلة احتباجات محددة بتطلبها الفرد و العمل الذي يؤديه ، فهو يهدف إلى تزويد الفرد معارف ومهارات وقدرات جديدة لتغيير سلوكه بشكل إيجابي(عبد الرحمن ، أمل ، لفئل

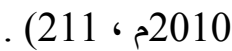

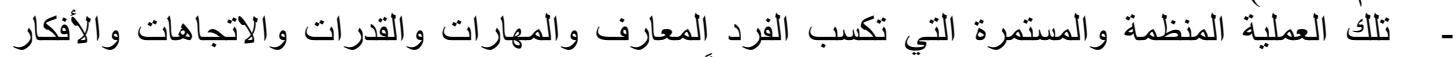

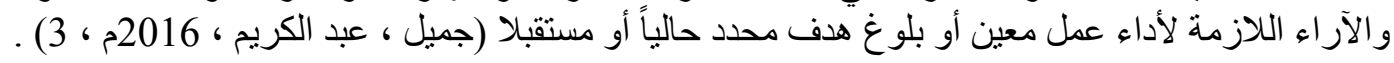

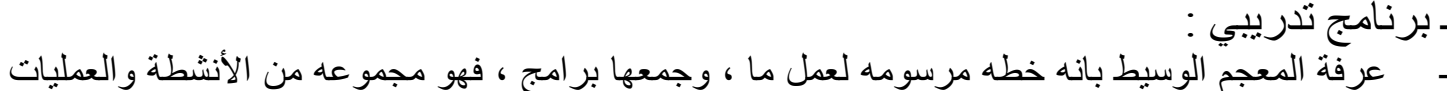
التي توجه نحو تحقيق أهداف محدده.

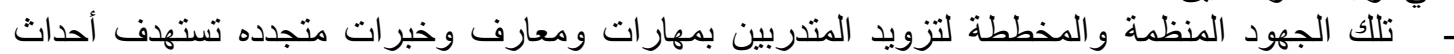

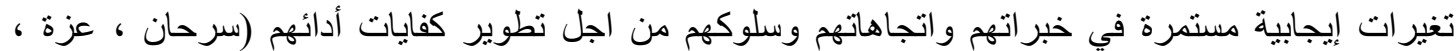

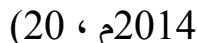
- بر امج مخططة ومنظمة تمكن المندربين من التمكن من مهار اتهم ، حيث يحصلون على خبرات معرفية

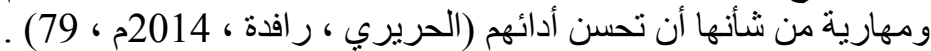

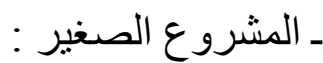

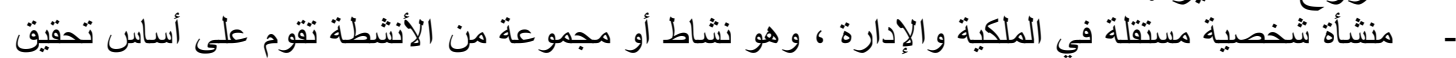

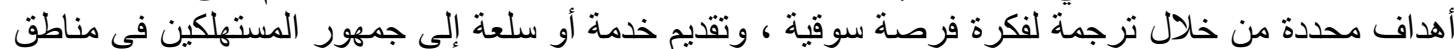

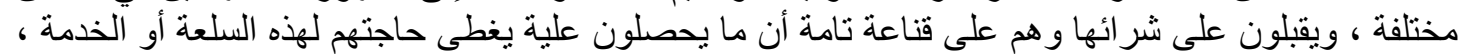

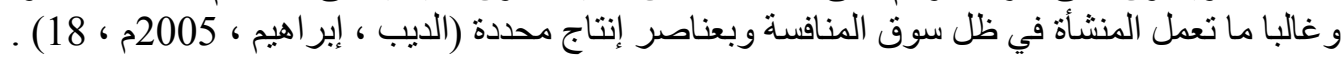

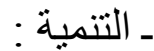
ـ الجهد المنظم لاستغلال الإمكانيات المادية والطاقات البشرية المتوفرة في المجتمع لتحقيق حاجاته الحقيقية

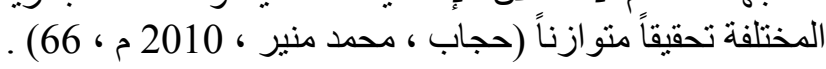

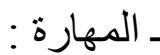
ـ ـ أداء عمل ما و إنجازه بدقة دون أخطاء في أسرع وقت وبأقل جهد ممكن (إبر اهيم ، مجدى عزيز ، 2004م ، - مجموعة استجابات الفرد الأدائية المتتاسقة التي تنمو بالتعلم و الممارسة حتى تصل إلى درجة عالية من الإتقان

$$
\text { منهج البحـث : زيتون ، حسن ، 2013م ،85) . }
$$

المنهج الثبة تجريبي : لاعتباره أقدر المناهج البحثية المناسبة لطبيعة الدراسة وعلاج المشكية الثكلة البحثية

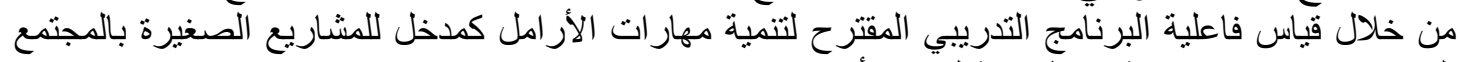
السعودي ، و إجر اء دراسة استطلاعية لتحقيق أهدافهه .

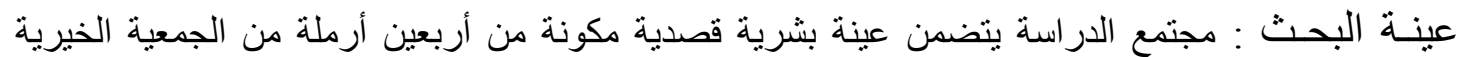

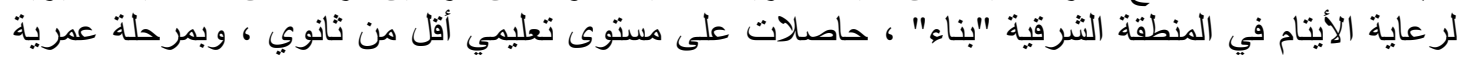




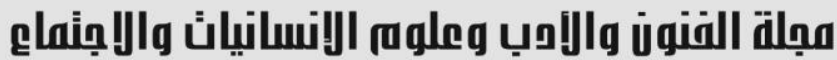

Journal of Arts, Literature, Humanities and Social Sciences www.jalhss.com

تعتمد الدر اسة على أكثر من أداة لجمع المادة العلمية المتعلقة بمشكلة الدر اسة للإجابة على تساؤلات الدات الدراسة ،

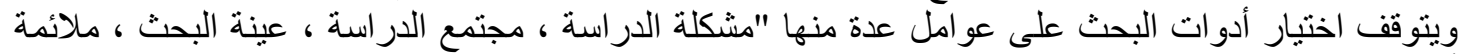

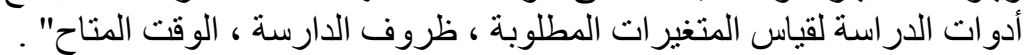

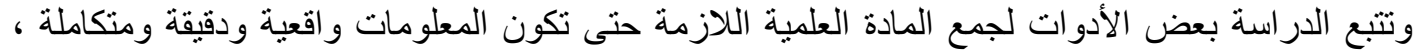
وتطبق أدو ات البحث باستخدام تطبيق (Google Drive) لبناء الاستبيانات و الاستمار ات الإلكترونية .

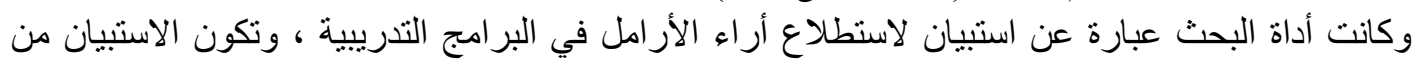

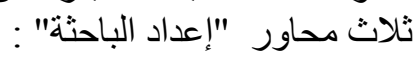

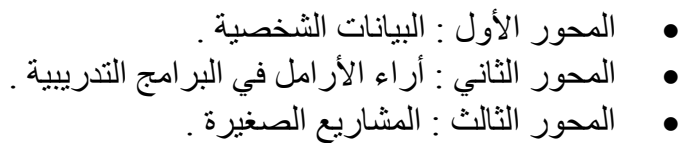

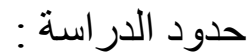

• حدود بشرية : تتكون الحدود البشرية من عدد أربعين أرملة تتر اوح أعمار هن "أقل من 35 سنة ، من 35 مائة

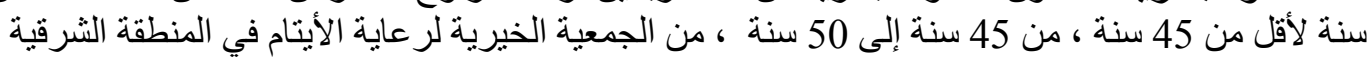
"بناء". هدود مكانية : المملكة العربية السعودية ـ المنطقة الثرقية ـ مدينة الخبر - الجمعية الخيرية لرعاية الأيتام في المنطقة الثرقية "بناء". • حدود الزمانية : استطلاع أراء الأرامل حول البرنامج التنريبي المقترح في المملكة العربية السعودية بمدينة الخبر في عام 2020م.

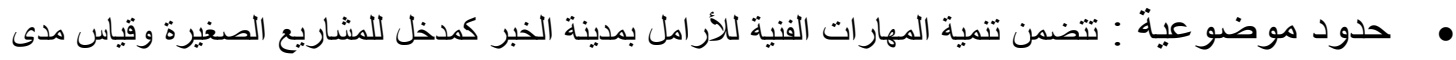

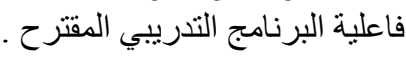

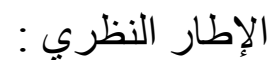

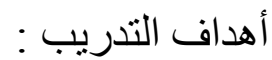
1. إكساب الأفراد المعارف و المهارات لإنجاز الأعمال على أكمل وجه ، مما يؤدي بدوره إلى رفع الكفاءة

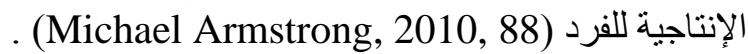

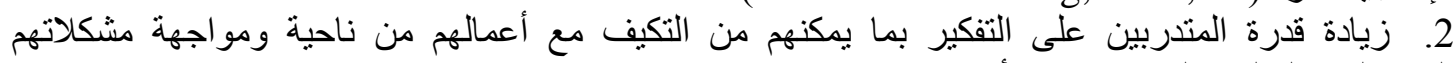

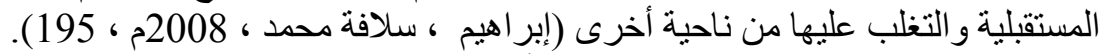

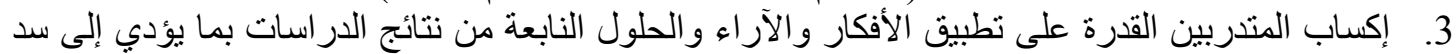
الفجوة بين النظرية و التطبيق العملي (Michael Armstrong, 2010, 88) . 4. الاستفادة من الطرق الحديثة للتندريب و التطوير لتنمية المعارف و المهار ات بأسلوب مرن وسهل (الطعاني ،

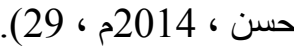
5 6. إعادة هندسة العملية التدريبية بمعرفة الأسس والمعايير التي بمكن من خلالها إجراء التعديلات لتطوير

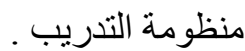
7. الاستخدام الأمثل للمو ارد باستغلال المهار ات المكتسبة (جميل ، عبد الكريم ، 2016م ، 15) .

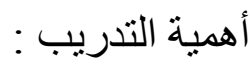
> التدريب هو الآلية التي تحرص على مو اكبة كل تغيير في كافة المجالات ، فبدون قوة بشرية مطورة وقادرة

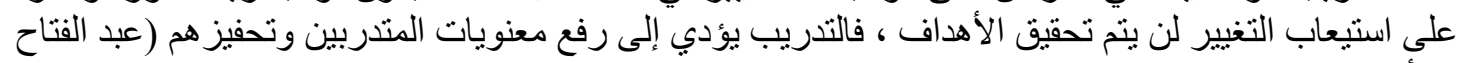

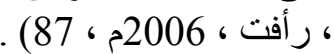

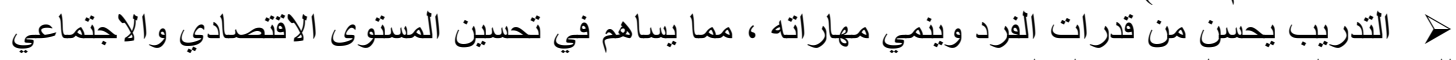

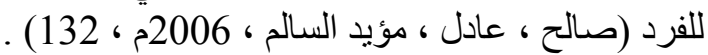

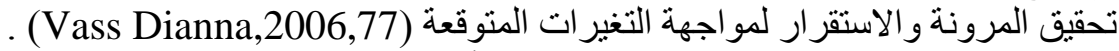

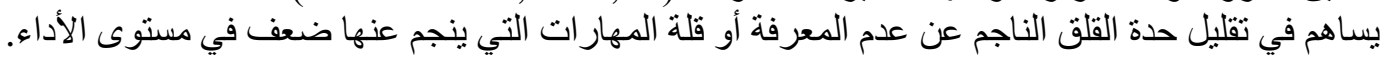




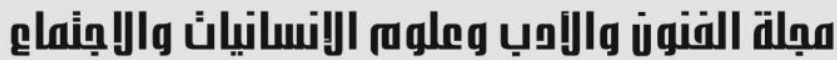

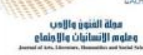

Journal of Arts, Literature, Humanities and Social Sciences

www.jalhss.com

ارتفاع معدل الإنتاجية و الأداء من خلال الوضوح في الأهداف وطرق وإجر اءات التنفيذ وتعريف الأفر اد بما

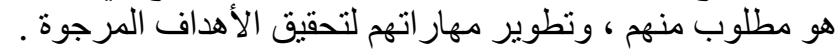

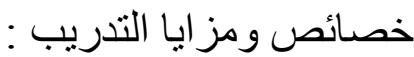

سهولة تعديل وتغيير طرق التدريب المستخدمة بالطريقة التي تناسب المتندبين ، فمنهم من تناسبه الطريقة

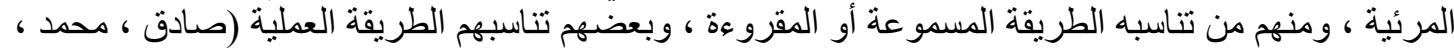

إتاحة الفرصة لتبادل الآراء و الخبر ات ، فينشئ التدريب علاقة تفاعلية بين المتدربين والمدربين (القادري ،

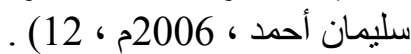

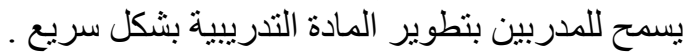
هيثجع المتدرب على الاعتماد على النفس و الوصول إلى مرحلة بناء المعرفة ذاتياً مما ينعكس علي ثقته بنفسه • ـ نوفير التفاعلية بين المتدرب و البرنامج التدريبي مما بسهل عرض المعلومات بصورة شيقة (محمود ، خالد

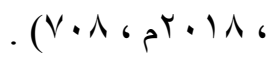

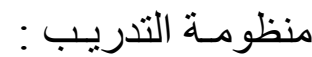

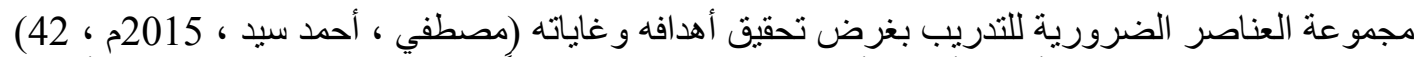

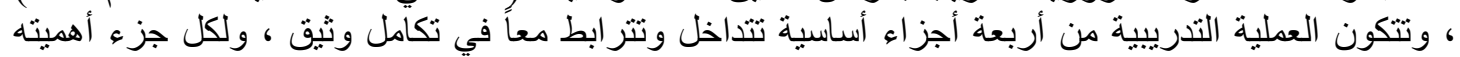

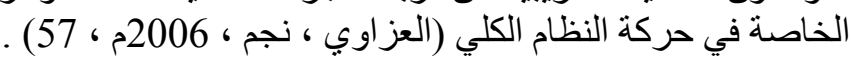

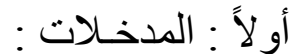

تعتبر المدخلات هي المكونات الأساسية التى يقوم عليها التدريب ، ويقصد بها التها الأجزاء المراد إخضاء إخهاعها

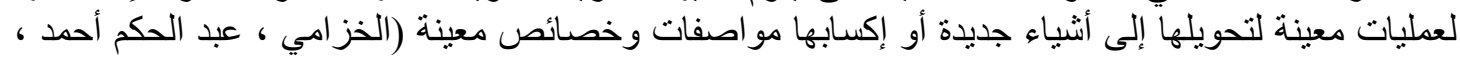
. 2003

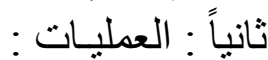
مجموعة الإجراءات التي تقوم بها إدارة التدريب من أجل الأداء الأمثل لتحقيق الأهداف ، تتضدمن هذه

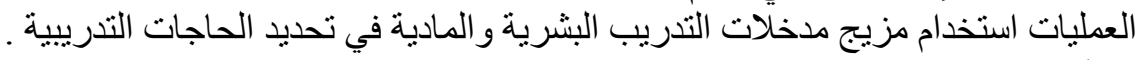

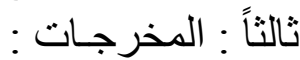

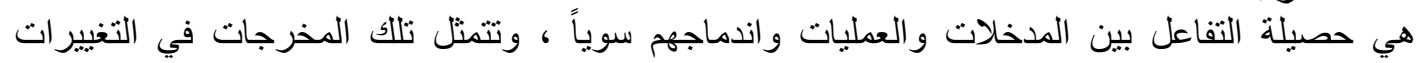

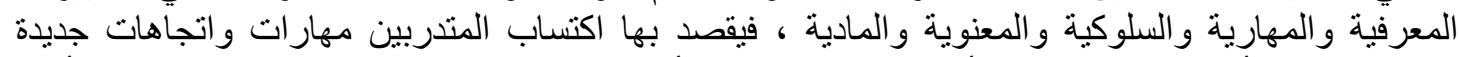

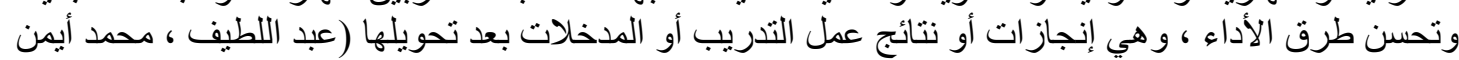

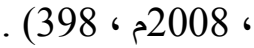

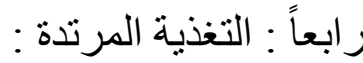

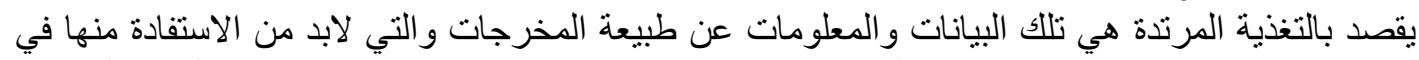

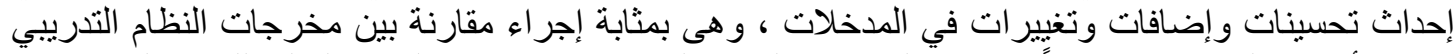

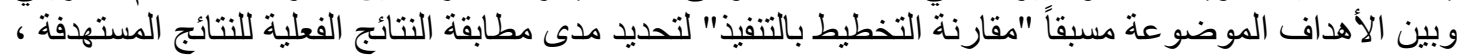

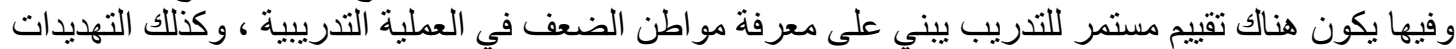
التي قد نو اجهها المنظمة مستقبلا ، ثم يلي ذلك عملية الإصلاح و التقويم لهذه العملية (عبد الو هاب ، على محمد ،

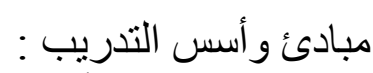

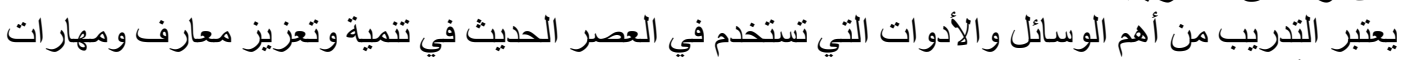

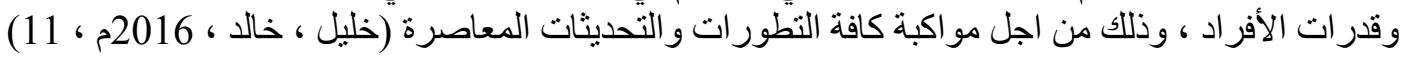
فالعملية التدريبية تخضع إلى عدة مبادئ عامة ينبخي مر اعاتها فى جميع مر احل هذه العملية وهي : (الخطيب، 


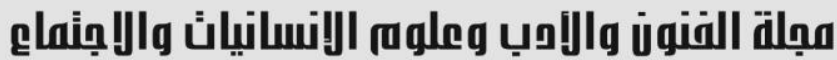

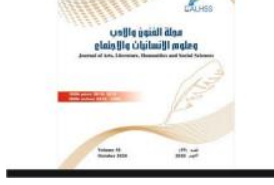

Journal of Arts, Literature, Humanities and Social Sciences

www.jalhss.com

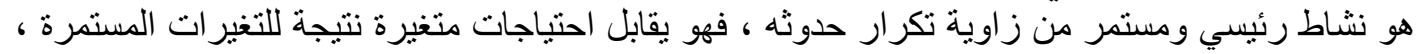

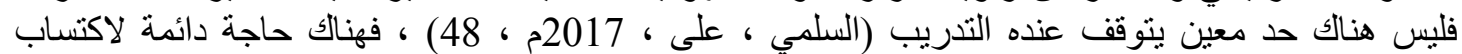

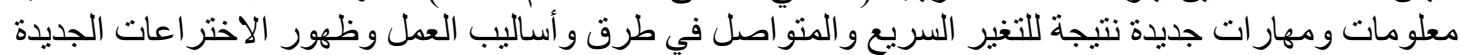
، فيعمل التدريب علي تكيفه مع التطور ات المستمرة الحالية والمستقبلية (عبد اللطيف ، محمد أيمن ، 2008م ،

ثانياً : التدريب نظام متكامل وليس نظام عشو ائي :

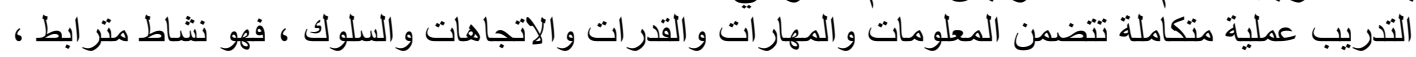

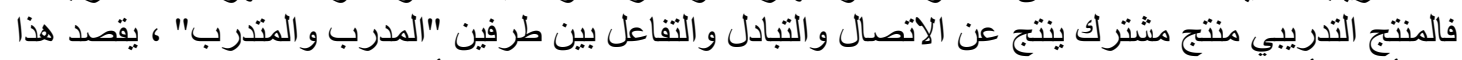

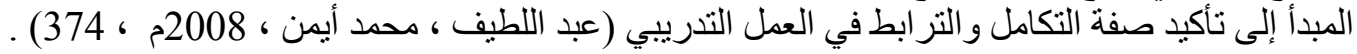

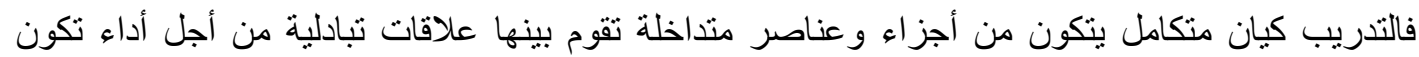

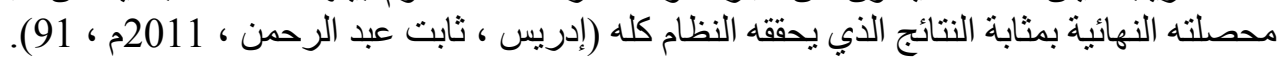

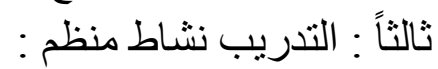
فالعملية التدريبية خاضعة للار اسة و البحث العلمي و لا تترك للممارسات و الاجتهادات غير المنظمة (عطا الله

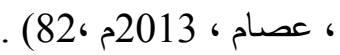

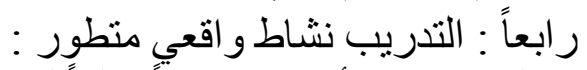

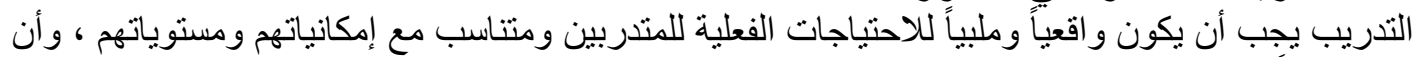

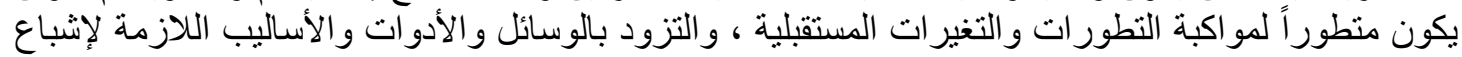

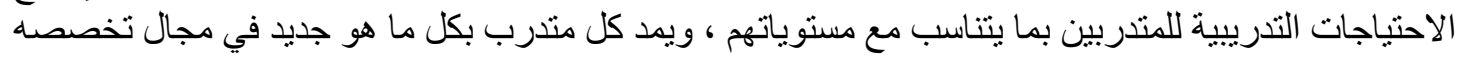

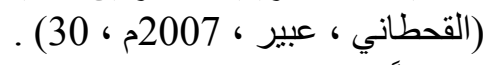

$$
\text { خامساً : التدريب نشانير ، بنداط تعاوني : }
$$

التدريب يعتمد على التعاون بين الأطر اف المختلفة المشتركة فيه ، وتتمثل في الإدارة و والمدرب و المتندرب ،

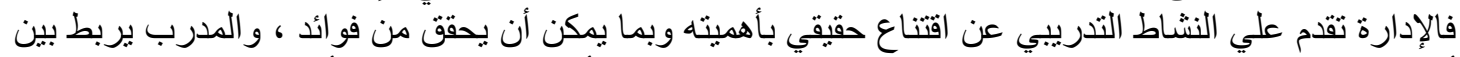

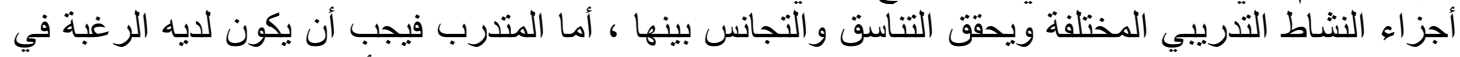

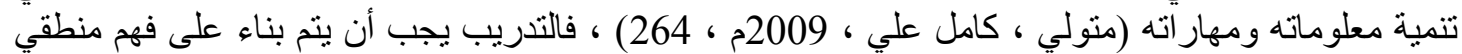

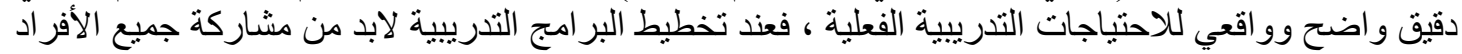

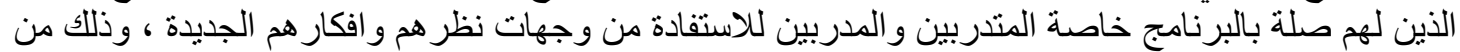
أجل أداء المهام بفاعلية وكفاءة لتحقيق الأهداف المرسومة (عساف ، عبد المعطى ، المبن ، 2014م ، 85) .

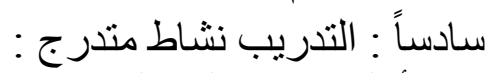

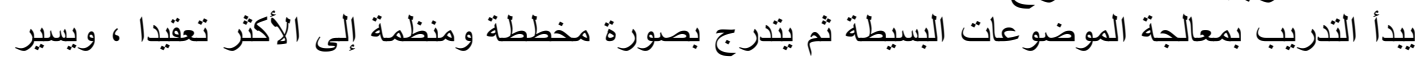

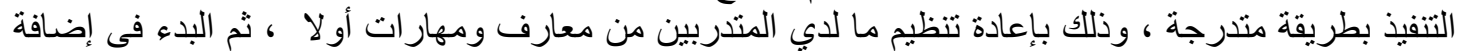

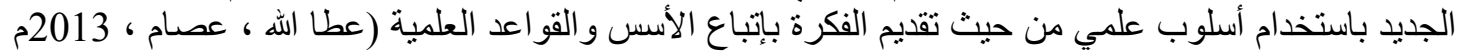

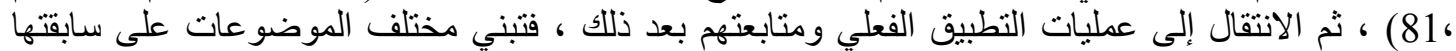

$$
\begin{aligned}
& \text { (عبد اللطيف ، محمد أيمن ، 2008م ، 373 31 ) . } \\
& \text { سابعاً : التدريب نشاط متعدد الاتجاهات : }
\end{aligned}
$$

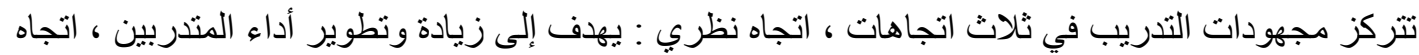

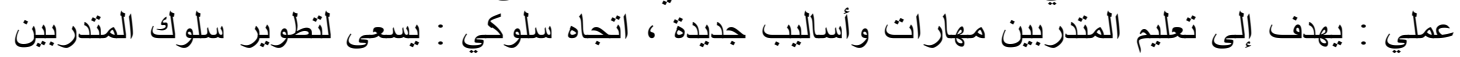

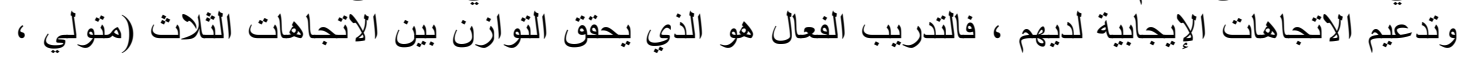

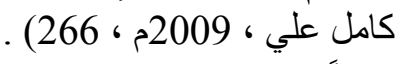

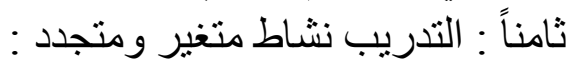

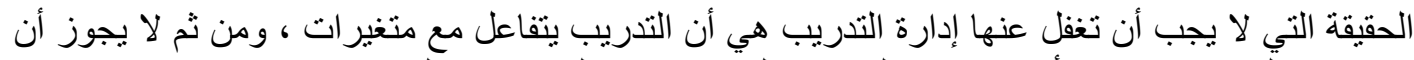

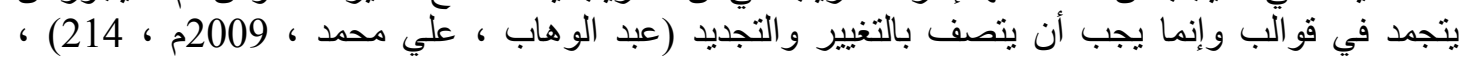




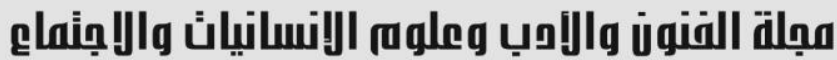

Journal of Arts, Literature, Humanities and Social Sciences www.jalhss.com

فالمتدرب يتعرض للتغيير في سلوكه ومهار اته ورغباته لتو اجه متطلبات العصر (دياب ، عبد الفتاح ، 2014م ،

تاسعاً : التدريب عملية إدارية وفنية :

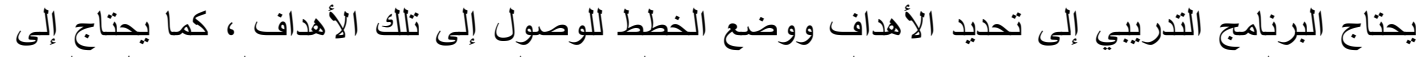

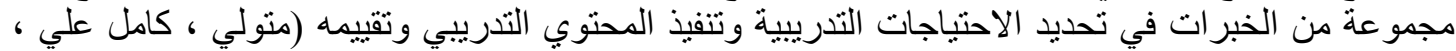

(266 ، 2009

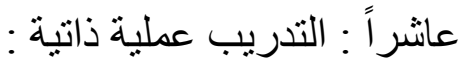

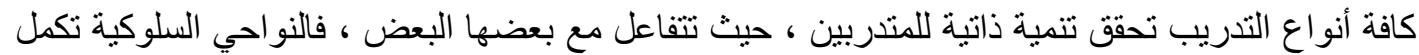

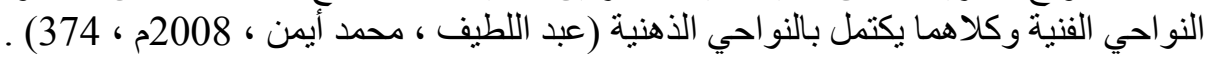

استر اتيجيات وسياسات التدريب النيات

يشير مصطلح السياسة إلى مجموعة القرارات والاتجاهات الصادرة من السلطة لمختصة لتحقيق أهداف

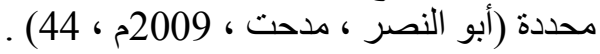

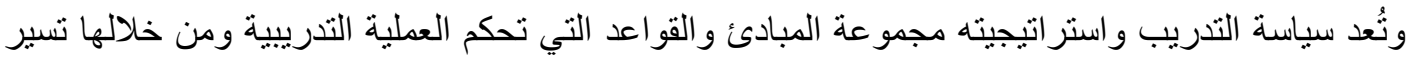

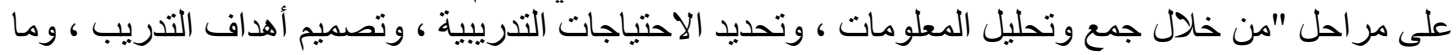

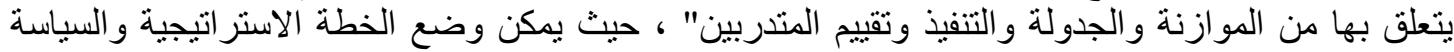

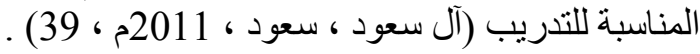

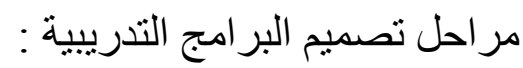

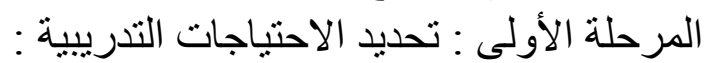

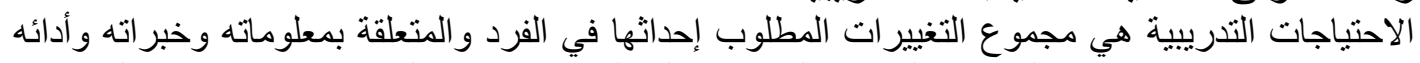

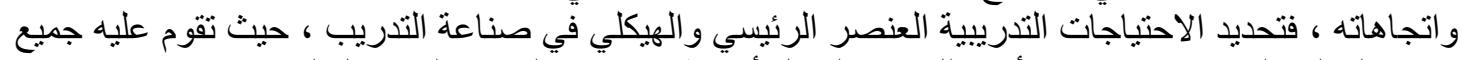

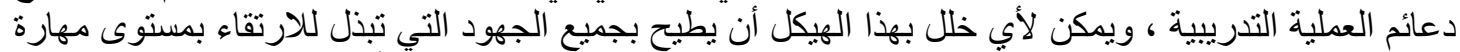

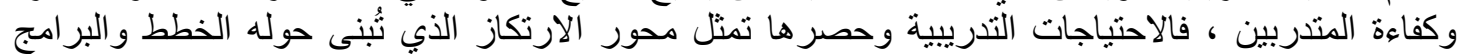

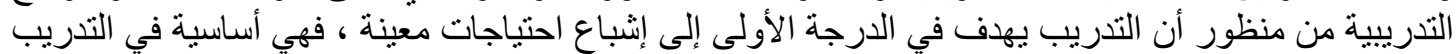

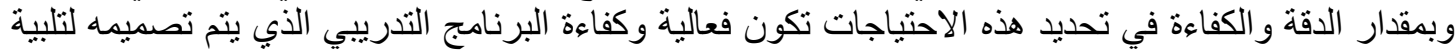

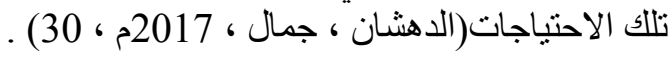

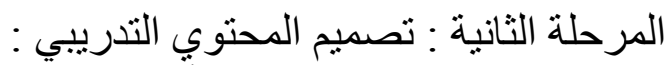

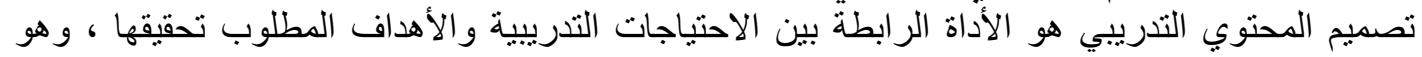

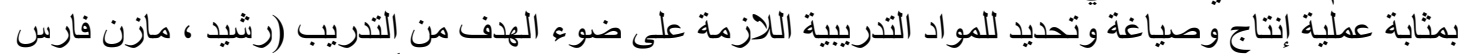

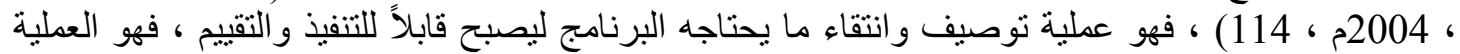

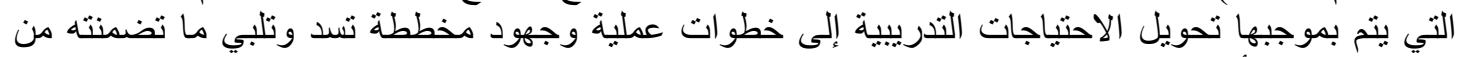

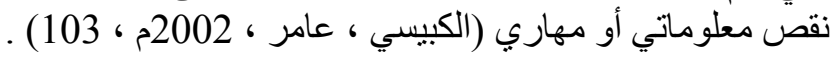

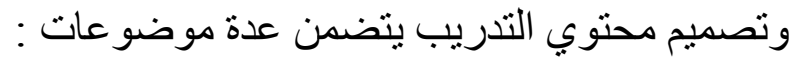

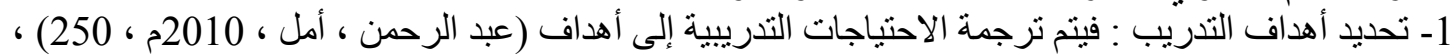

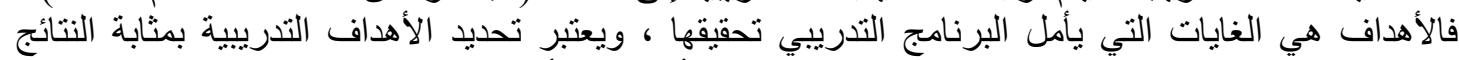

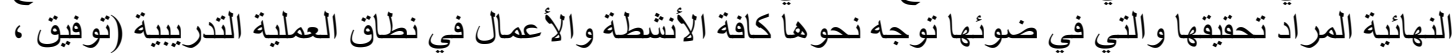

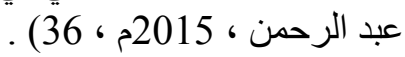

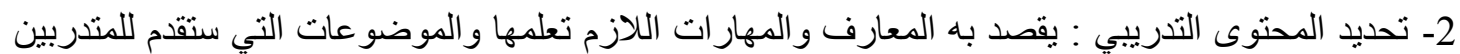
خلال التدريب و التسلسل المنطقي للمحتوى (David Osboran, 2006, 225) .

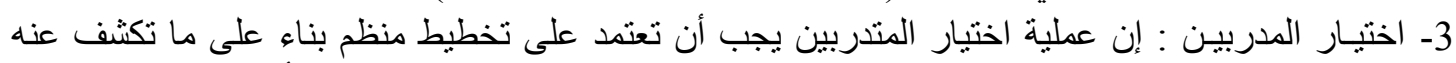

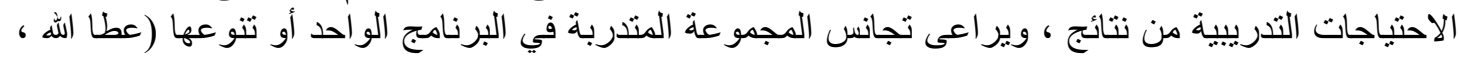

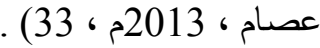

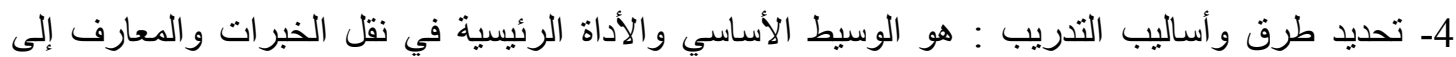
المتدرب وفقا لطبيعة احتياجاته التدريبية (خليل ، سعد الدين ، 2013م ، 91 91الايب ) . 


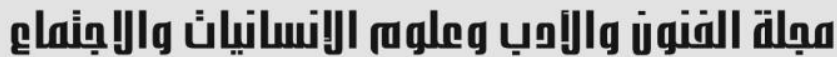

Journal of Arts, Literature, Humanities and Social Sciences www.jalhss.com

المرحلة الثالثة : تنفيذ المحتوي التدريبي :

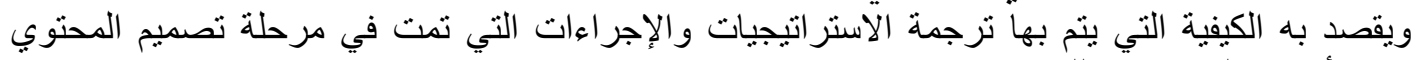

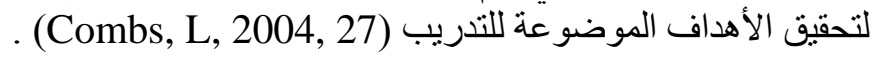

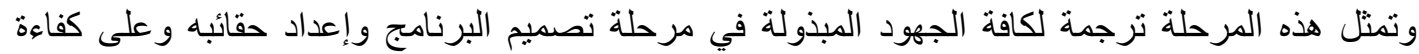

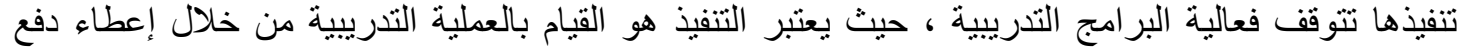

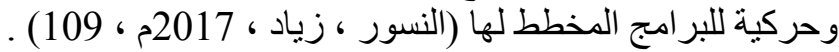

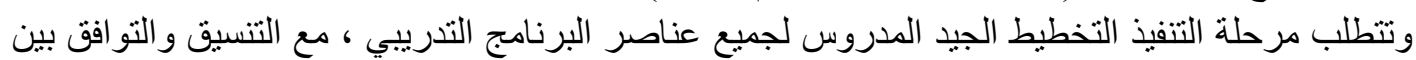

جهات التخطيط وجهات التنفيذ لضمان نجاح التنفيذ (محمد ، عقلة ، 2012م ، 38 38 ) .

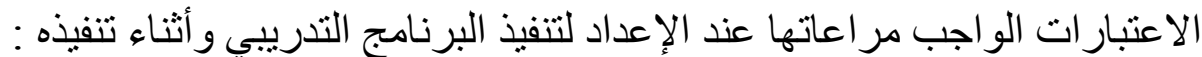

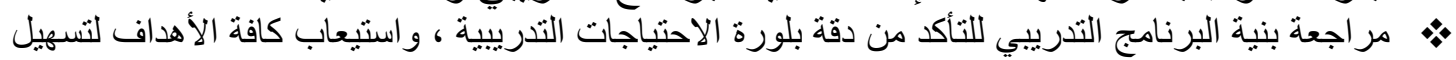

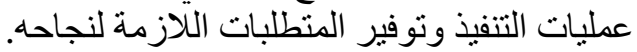

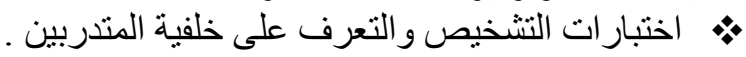

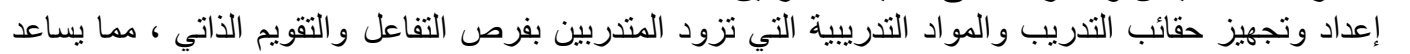
على سهولة وتيسير العملية التدريبية.

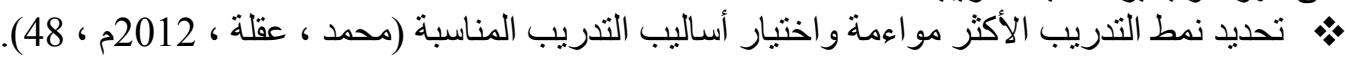

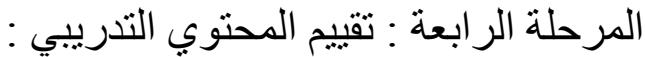

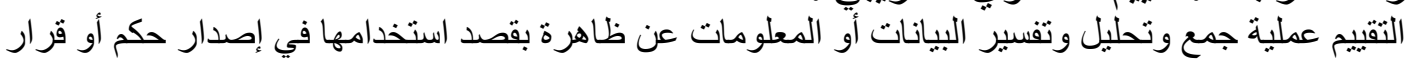

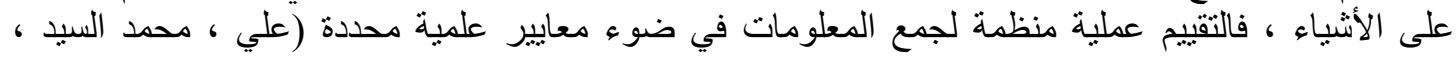

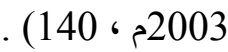

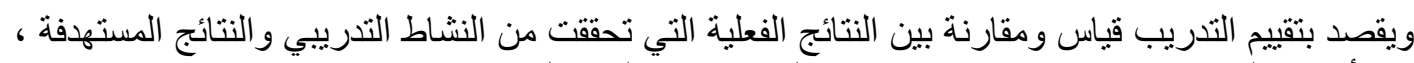

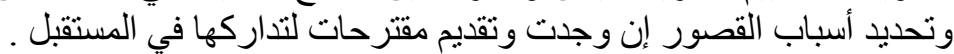
كيفية إنجاح البر امج التدريبية : لتفعيل دور البر امج التدرييية لابد من وضع استر التئ اتيجية تتمنل في :

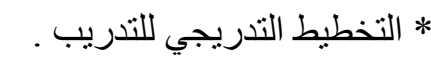

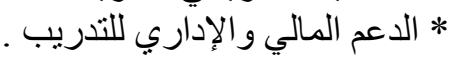

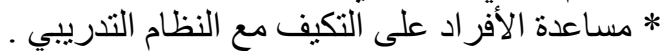
* الدقة في اختيار المصمين لتصميم وتنفيذ البرنامج التنريبي (عبد الوهاب ، محمد علي ، 2009م ، 242 ،

العو امل المؤثرة في فعالية التدريب :

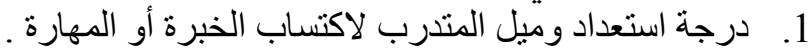

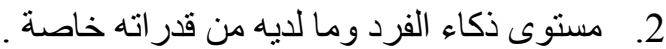

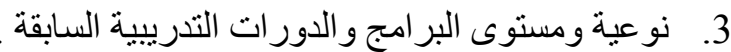

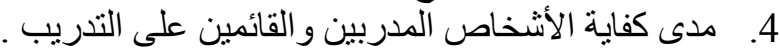

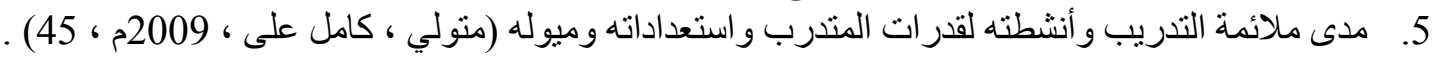

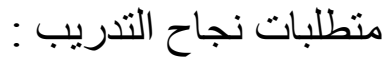
م تمانشى العقلية الإدارية المسئولة عن التدريب مع طبيعة التدريب .

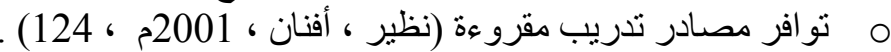

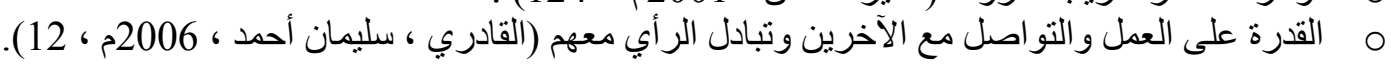

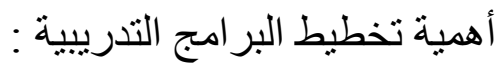

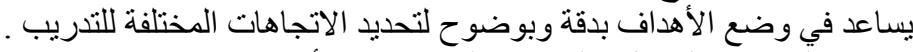

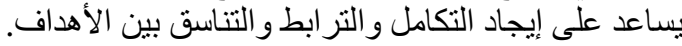

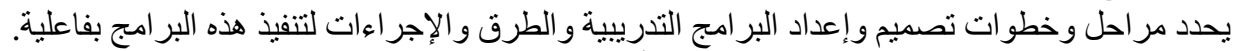

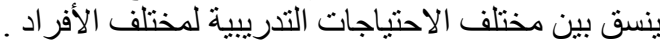
يحدد أفضل طرق التدريب. 


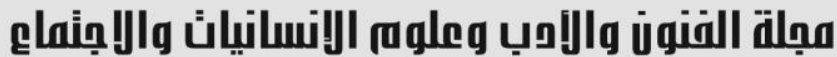

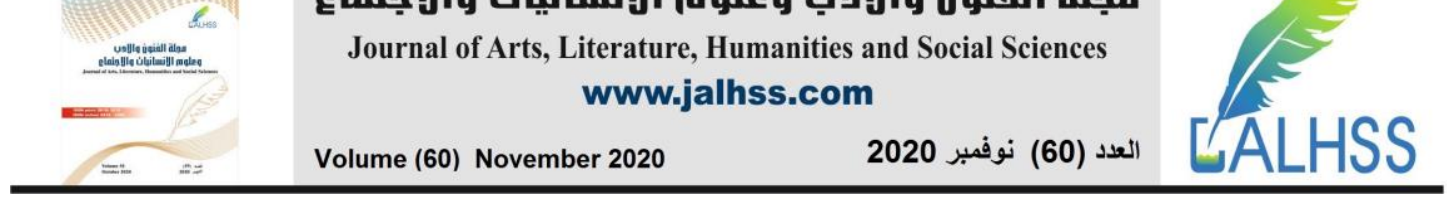

• ينظم ويرتب عملية التدريب (عبد الفتاح ، محمد ، 2014م ، 66) .

$$
\begin{aligned}
& \text { النتائج الوصفية : } \\
& \text { وفيما يلي وصف للبيانات العامة لعينة الدر اسة : } \\
& \text { المحور الأول : "البيانات الثخصية" } \\
& \text { 1- المستوى التعليمي : }
\end{aligned}
$$

\begin{tabular}{|c|c|c|}
\hline النسبة\%\% & العدد ا ل العد & المستوى التعليمى \\
\hline$\% 45$ & 18 & الثهادة الابتدائية فأقلّ \\
\hline$\% 37.5$ & 15 & الثهادة المتوسطة \\
\hline$\% 17.5$ & 7 & الثهادة الثانوية \\
\hline \%100 & $\overline{40}$ & المجموع \\
\hline
\end{tabular}

يوضح الجدول (1) والثكل البياني رقم (1) توزيع عينة البحث تبعا لمتغير المستوى التعليمي . جدول (1) توزيع عينة البحث تبعا لمتغير المستوى التعليمي

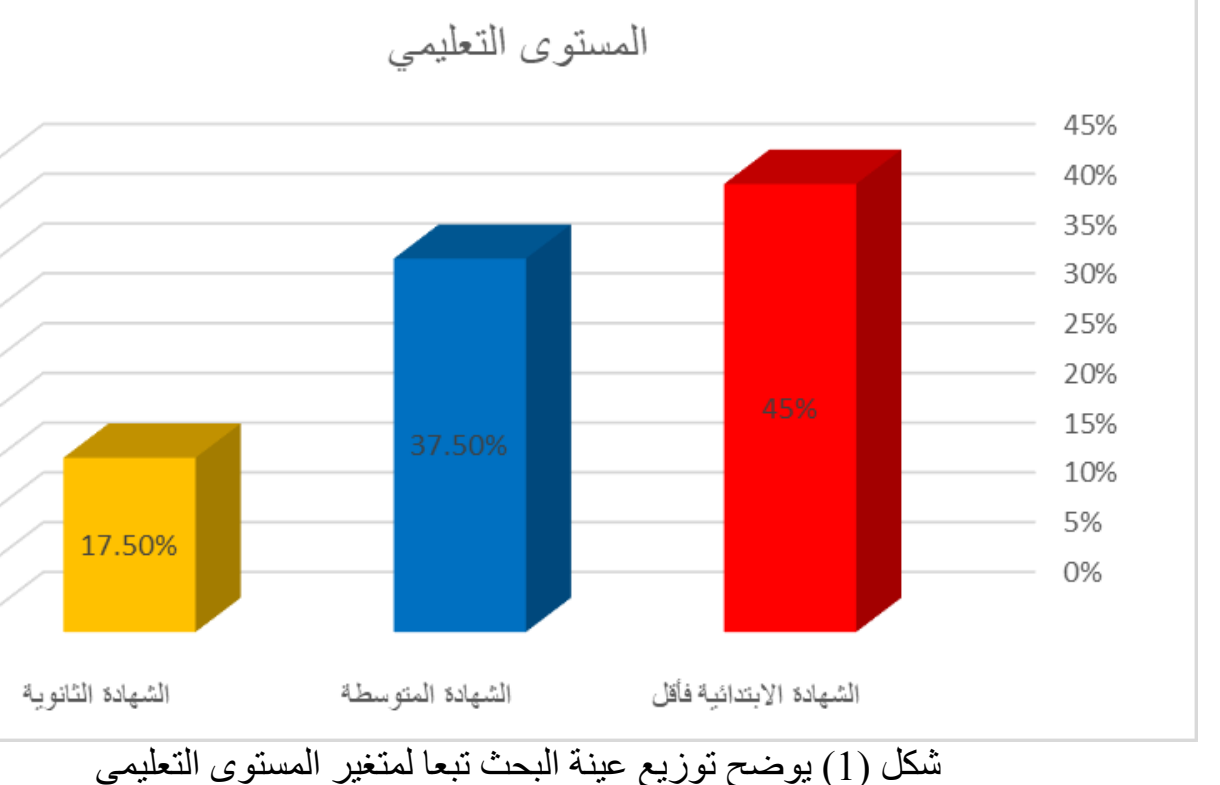

$$
\text { شكل (1) يوضح توزيع عينة البحث تبعا لمتغير المستوى التعليمي }
$$

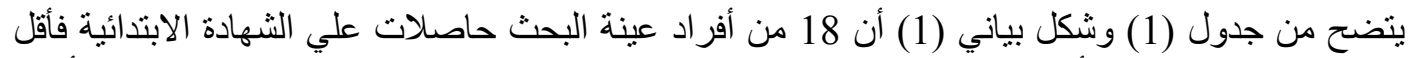

\begin{tabular}{|c|c|c|}
\hline النسبة\%\% & 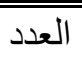 & العمر \\
\hline$\% 22.5$ & 9 & أقل من 35 سنة \\
\hline$\% 35$ & 14 & من 35 سنة لأقل من 45 سنة \\
\hline$\% 42.5$ & 17 & من 45 سنة فأكثر \\
\hline$\% 100$ & 40 & المجموع \\
\hline
\end{tabular}

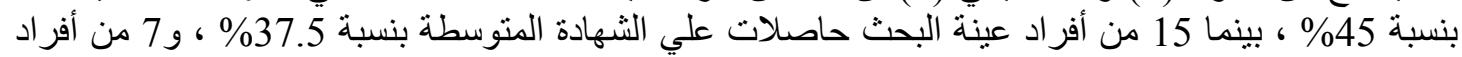

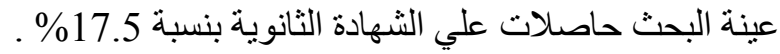

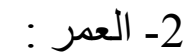

يوضح الجدول (2) و الثكل البياني رقم (2) توزيع عينة البحث تبعا لمتغير العمر . 


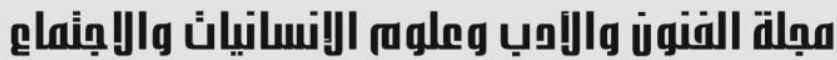

Journal of Arts, Literature, Humanities and Social Sciences www.jalhss.com

Volume (60) November 2020 العدد (60) نوفمبر 2020 ¿ALHSS

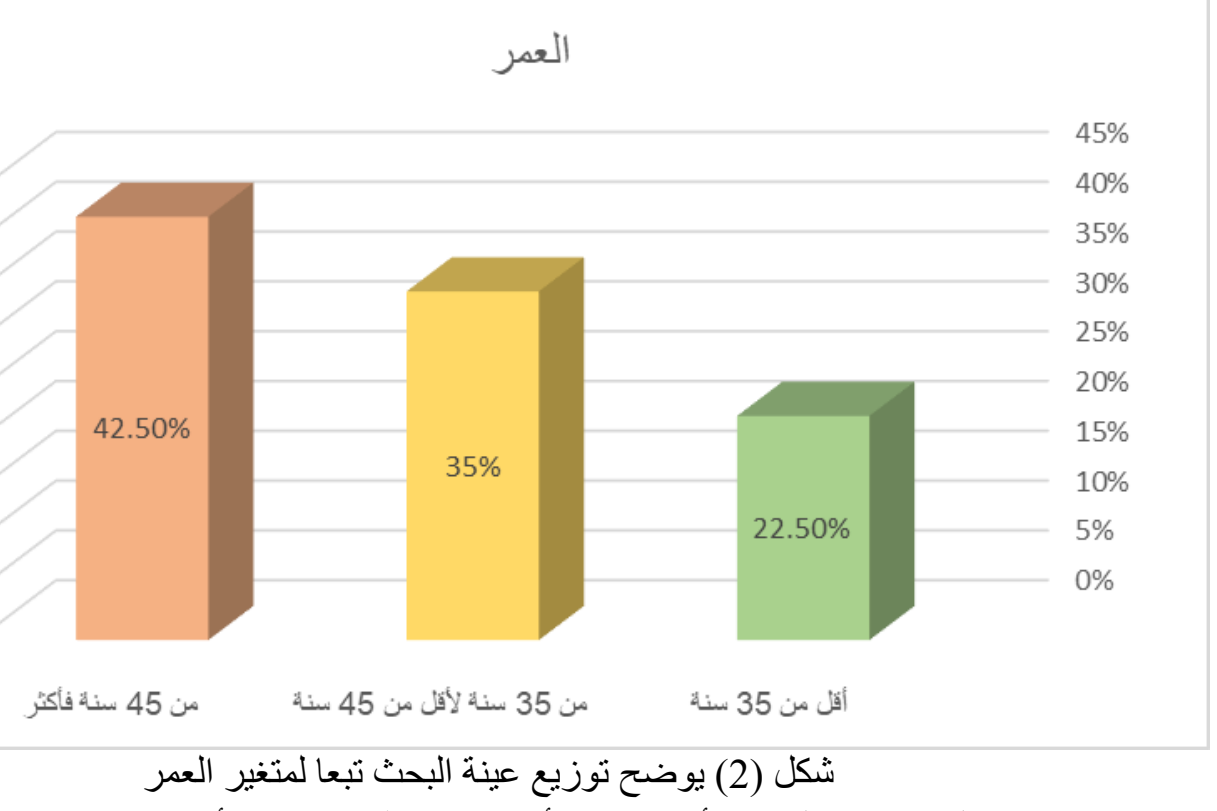

يتضح من جدول (2) وشكل (2) أن 17 من أفراد عينة البحث كانت أعمار هن من 45 من سنة فئة فأكثر بنسبة

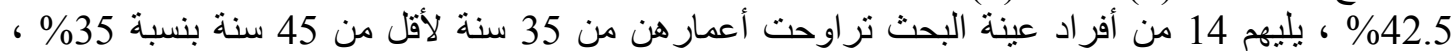

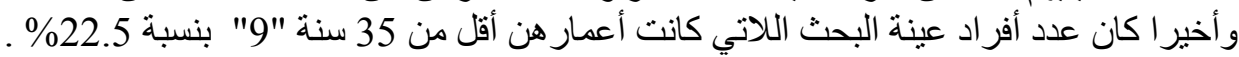

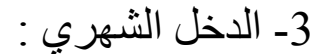

يوضح الجدول (3) و الثكل البياني رقم (3) توزيع عينة البحث وفقا لفئات الدخل المختلفة . جدول (3) توزيع عينة البحث وفقا لفئات الدخل المختلفة

\begin{tabular}{|c|c|c|}
\hline النسبة\%\% & 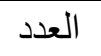 & الدخل الشهري \\
\hline$\% 67.5$ & 27 & منخفض \\
\hline$\% 32.5$ & 13 & منوسط \\
\hline$\% 100$ & 40 & المجموع \\
\hline
\end{tabular}

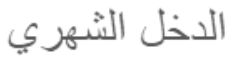

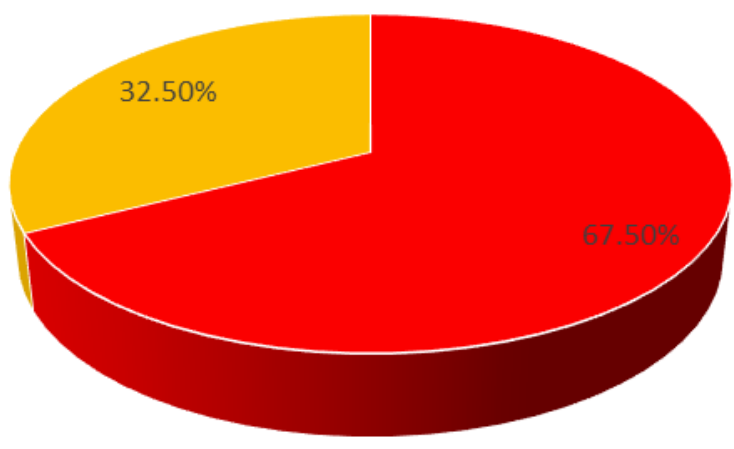

" مثوسط" منظفض

شكل (3) يوضح توزيع عينة البحث وفقا لفئات الدخل المختلفة 


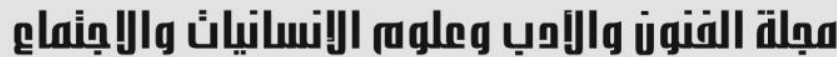

Journal of Arts, Literature, Humanities and Social Sciences www.jalhss.com

يتضح من جدول (3) وشكل (3) أن 27 من أفر اد عينة البحث دخلهم منخفض بنسبة 67.5\% ، بينما 13 من

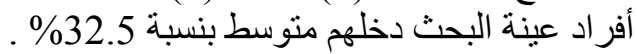

$$
\begin{aligned}
& \text { المحور الثاني : "أر اء الأرامل في البرامج التدريبية" } \\
& \text { 1- هل تر غبين في حضور برنامج تدريبي : }
\end{aligned}
$$

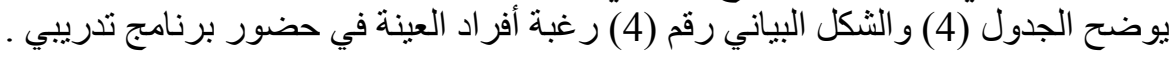

\begin{tabular}{|c|c|c|}
\hline النسبة\%\% & العدد & الرغبة في حضور برنامج تدريبي \\
\hline$\% 66.7$ & 40 & أو افق \\
\hline$\% 23.3$ & 14 & أو افق إلى حد ما \\
\hline$\% 10$ & 6 & لا أو افق \\
\hline$\% 100$ & 60 & المجموع \\
\hline
\end{tabular}

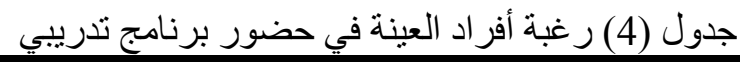

$$
\text { الرغبة في حضور برناهج تدريبي }
$$

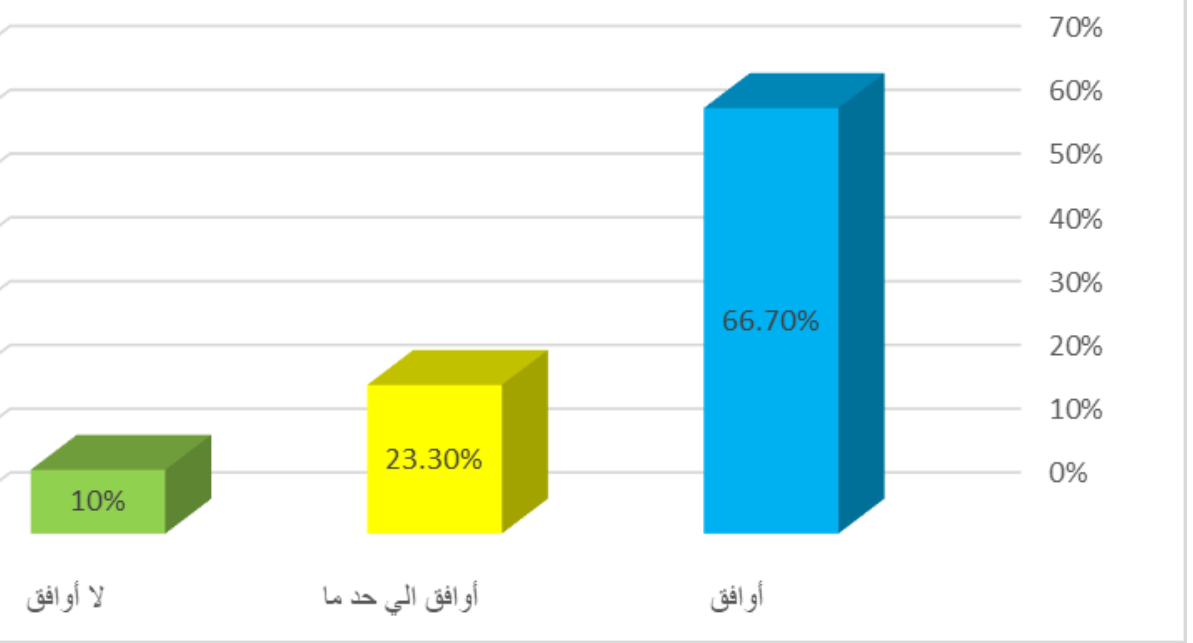

$$
\text { شكل (4) يوضح رغبة أفراد العينة في حضور برنامج تدريبي }
$$

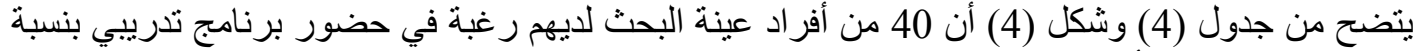

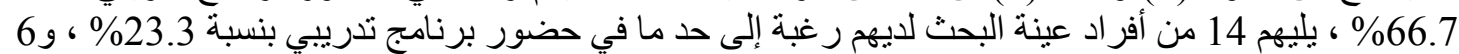

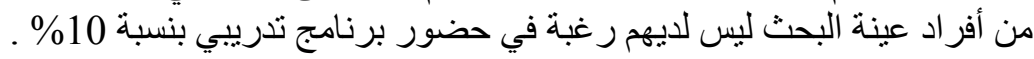

\begin{tabular}{|c|c|c|}
\hline النسبة\%\% & 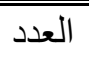 & المجال التدريبي للبرنامج الذي تفضلين حضوره \\
\hline$\% 32.5$ & 13 & برنامج تدريبي في مجال الخياطة والتفصيل \\
\hline$\% 10$ & 4 & برنامج تدريبي في مجال التطريز \\
\hline$\% 57.5$ & 23 & برنامج تدريبي في مجال الفنون "فن الفسيفساء الدقيقة" \\
\hline$\% 100$ & 40 & المجمو ع \\
\hline
\end{tabular}

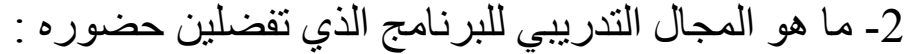

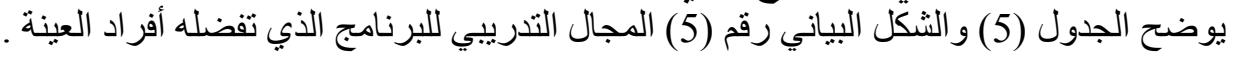
جدول (5) المجال التدريبي للبرنامج الذي تلفضله الفي أفراد العينة 


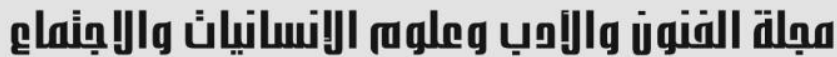

Journal of Arts, Literature, Humanities and Social Sciences
www.jalhss.com

المجال التدريبي للبرنامج الذي تفضلين حضوره

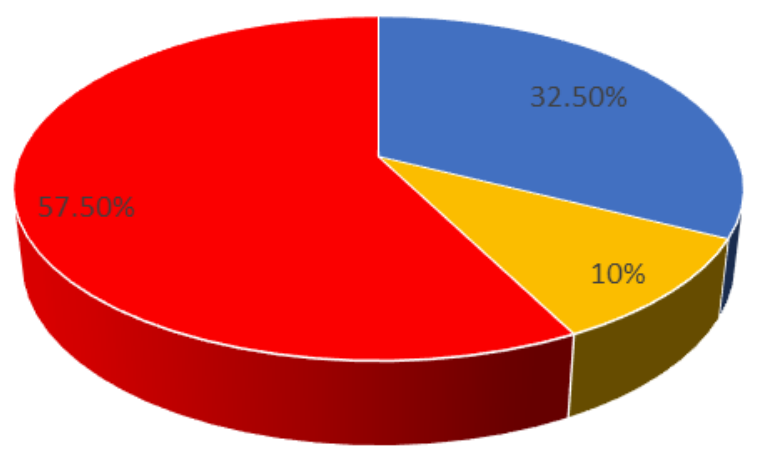

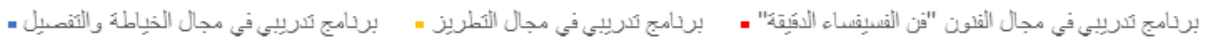

$$
\text { شكل (5) يوضح المجال التدريبي للبرنامج الذي تفضله أفر اد العينة }
$$

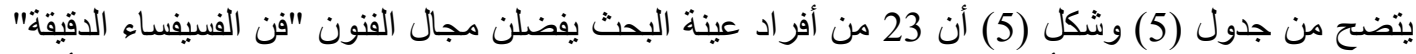

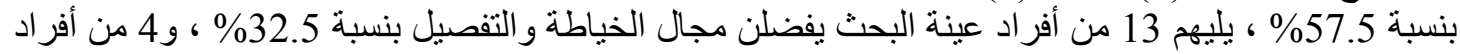

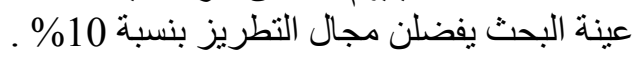

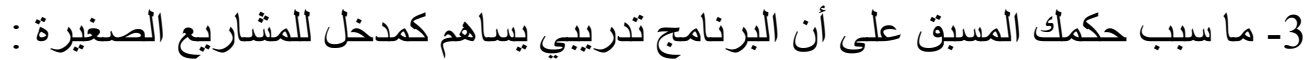

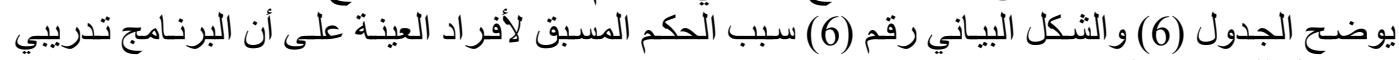
يساهم كمدخل للمشاريع الصغيرة . جدول (6) سبب الحكم المسبق لأفر اد العينة على أن البرنامج تدريبي يساهم كمدخل للمشاريع الصغيرة

\begin{tabular}{|c|c|c|}
\hline 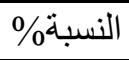 & العدد & البرنامج تدريبي يساهم كمدخل للمشاريع الصغيرة \\
\hline$\% 10$ & 4 & خبرة مسبقة في حضور برنامج تدرييي \\
\hline$\% 5$ & 2 & رأي إدر الك شخصي \\
\hline$\% 15$ & 6 & معلومات عن البرامج التدرييية من أفر اد الأسرة أو الأصدقاء \\
\hline$\% 7.5$ & 3 & سمعة البر امج التنرييية \\
\hline$\% 17.5$ & 7 & معلومات من الأنترنت "المدونات ، المنتديات" \\
\hline$\% 20$ & 8 & معلو مات من وسائل التو اصل الاجتماعي مثل "الانستغر ام ، سناب شاب ، تويتر" \\
\hline$\% 25$ & 10 & معلومات من وسائل الإعلام "مثل التلفزيون و الإذاعة و المجلات وما إلى ذلك" \\
\hline$\% 100$ & 40 & 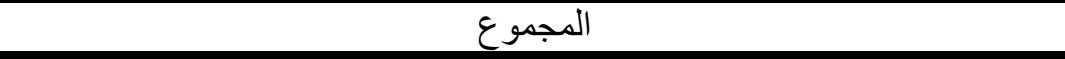 \\
\hline
\end{tabular}




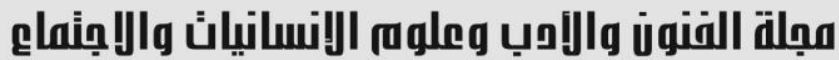

Journal of Arts, Literature, Humanities and Social Sciences www.jalhss.com

البرنامج تدريبي يساهم كمدخل للمشاريع الصغيرة

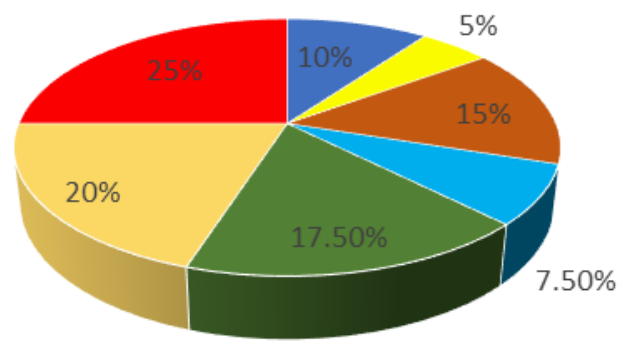

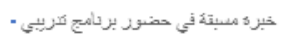

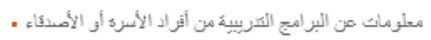

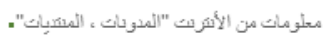

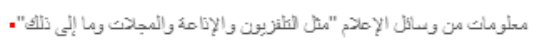

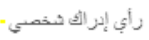

سمعة البرامج النتريبية.

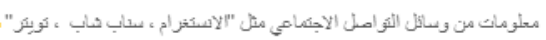

شكل (6) يوضح سبب الحكم المسبق لأفر اد العينة على أن البرنامج تدريبي يساهم كمدخل للمشاريع الصغيرة

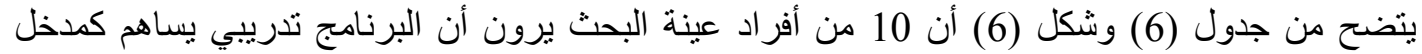

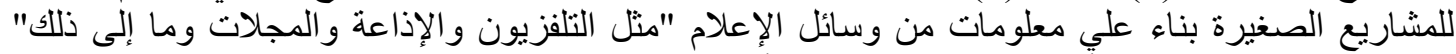

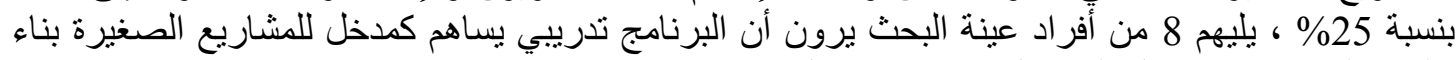

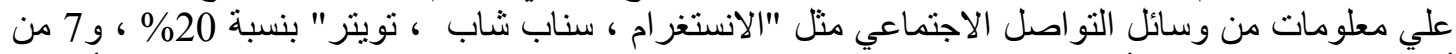

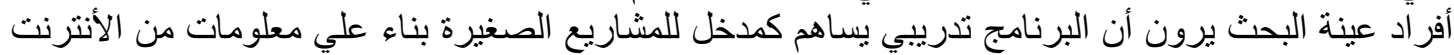

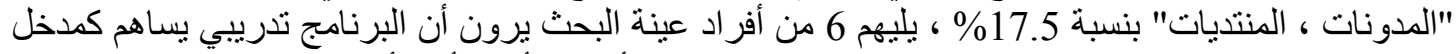

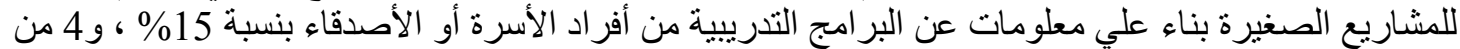

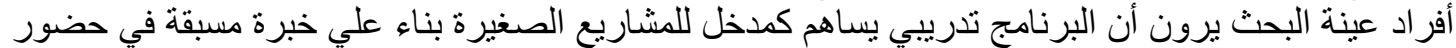

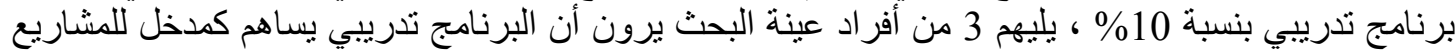

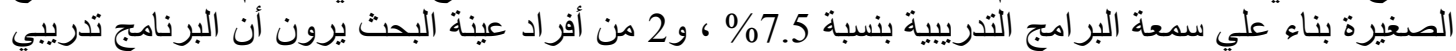

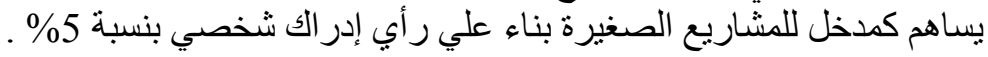

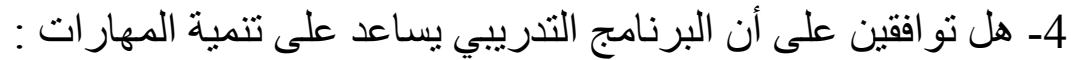
يوضح الجدول (7) و الثكل البياني رقم (7) هل يو الفق أفر اد العينـة على أن البرنـامج التدريبي يسـاعد على التى

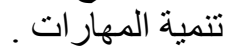

جدول (7) هل يو افق أفر اد العينة على أن البرنامج التدريبي يساعد على تتمية المهار ات

\begin{tabular}{|c|c|c|}
\hline النسبة\%\% & 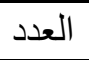 & البرنامج تدريبي يساعد على تتمية المهار ات \\
\hline$\% 65$ & 26 & أو أو افق \\
\hline$\% 27.5$ & 11 & أو افق إلى حد ما \\
\hline$\% 7.5$ & 3 & لا أو افق \\
\hline$\% 100$ & 40 & 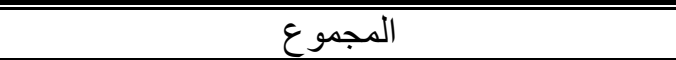 \\
\hline
\end{tabular}




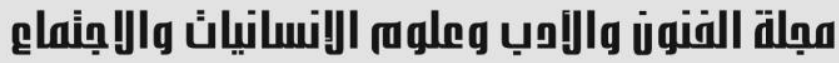

Journal of Arts, Literature, Humanities and Social Sciences www.jalhss.com

\section{البرنامج تدريبي يساعد على تنمية المهارات}

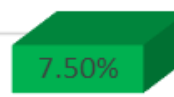

لا أو افق

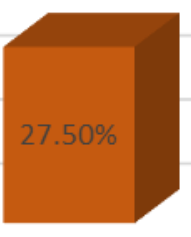

أو افقى

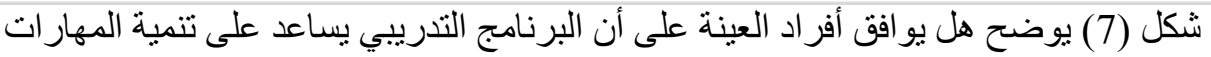

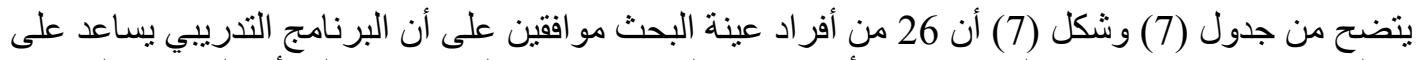

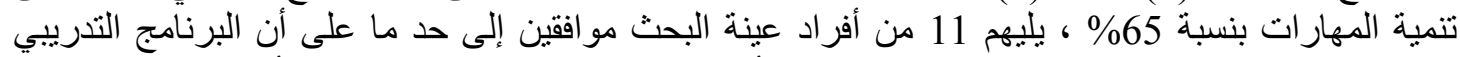

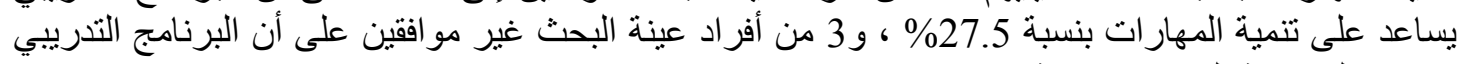
يساعد على تنمية المهار ات بنسبة 7.5\% . المحور الثالث : المشاريع الصغيرة

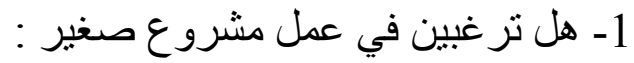

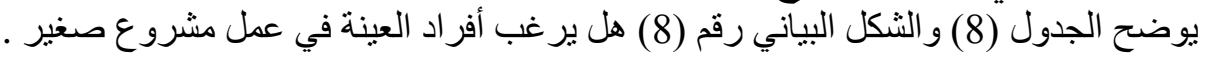
جدول (8) هل بر غب أفر اد العينة في عمل مشروع صغغير

\begin{tabular}{|c|c|c|}
\hline 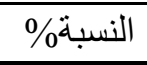 & العدد & الرغبة في عمل مشرو ع صغير \\
\hline$\% 65$ & 26 & أو افق \\
\hline$\% 22.5$ & 9 & أو افق إلى حذ ما \\
\hline$\% 12.5$ & 5 & لا لأو افق \\
\hline$\% 100$ & 40 & 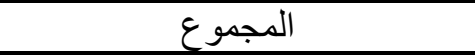 \\
\hline
\end{tabular}




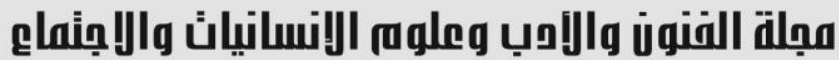

Journal of Arts, Literature, Humanities and Social Sciences www.jalhss.com

Volume (60) November 2020 العدد (60) نوفمبر 2020

$$
\text { الرغبة في عمل مشروع صغير }
$$

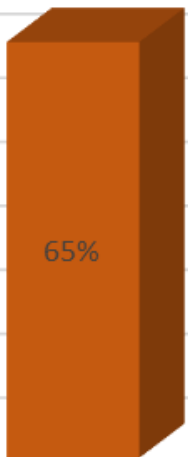

$$
\text { شكل (8) يوضح هل يرغب أفر اد العينة في عمل مشروع صغير }
$$

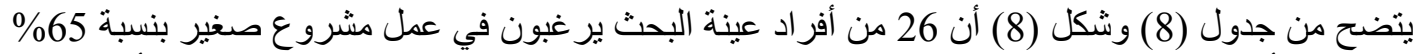

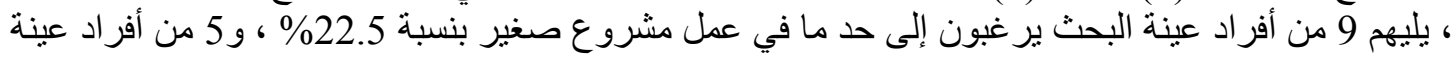

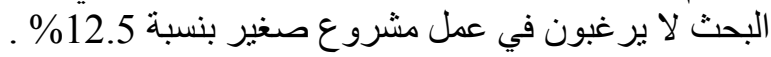

$$
\text { 2- ما هي الأسباب التي تحول بينك وبين عمل مشروع صغير صغير : }
$$

\begin{tabular}{|c|c|c|}
\hline النسبة\% & 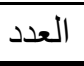 & الأسباب التي تحول بينك وبين عمل مشروع صغير \\
\hline$\% 17.5$ & 7 & عدم توفر تمويل أو دعم مادي \\
\hline$\% 40$ & 16 & لا أملك مهار ات تدريبية \\
\hline$\% 22.5$ & 9 & احتاج إلى تتمية مهار اتي التذريبية \\
\hline$\% 7.5$ & 3 & عو امل شخصية مثل "ضغوط أسرية" \\
\hline$\% 12.5$ & 5 & عدم توفر الوقت \\
\hline$\% 100$ & 40 & المجموع \\
\hline
\end{tabular}
يوضح الجدول (9) و الثكل البياني رقم (9) الأسباب التي تحول بين أفر اد العينة وبين عمل مشروع صغير

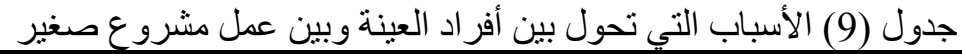




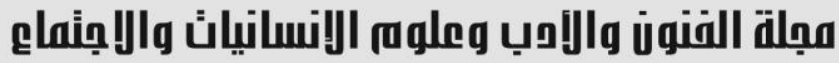

Journal of Arts, Literature, Humanities and Social Sciences www.jalhss.com

Volume (60) November 2020 العدد (60) نوفمبر 2020

الأسباب التي تحول بينك وبين عمل مشروع صغير

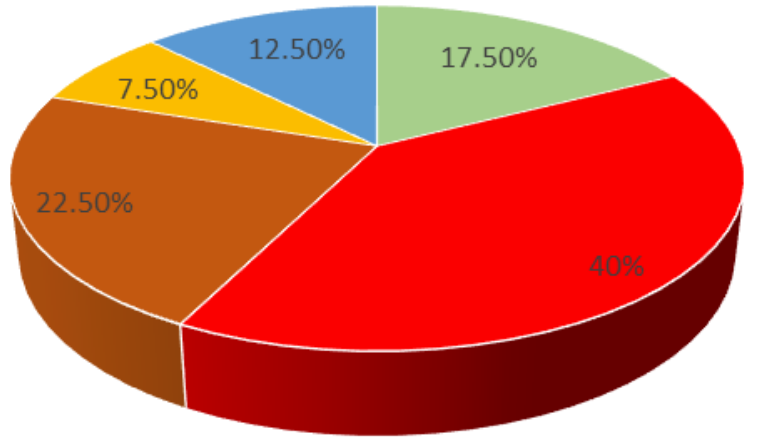

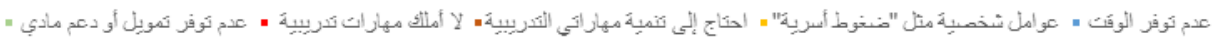

شكل (9) يوضح الأسباب التي تحول بين أفر اد العينة وبين عمل مشروع صغير

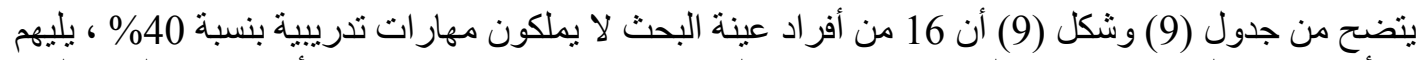

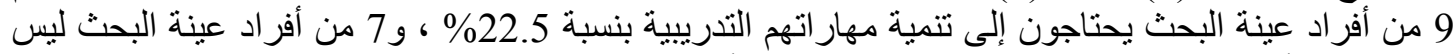

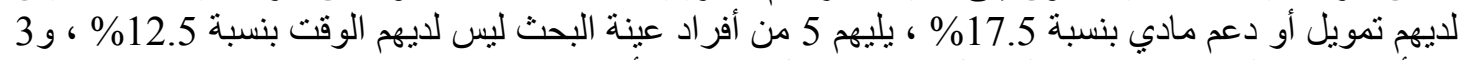

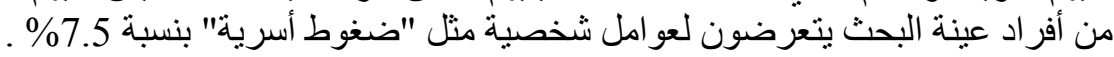

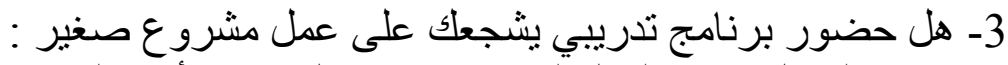
يوضح الجدول (10) و الثكل ألبياني رقم (10) هل حضور أفراد العينـة برنـامج تدريبي يشجعهم على عمل مشروع صغير جدول (10) هل حضور أفر اد العينة برنامج تدريبي يشجعه على عمل مشروع صغير

\begin{tabular}{|c|c|c|}
\hline النسبة\%\% & العدد & حضور برنامج تدريبي يشجع مشروع صغير \\
\hline$\% 70$ & 28 & أو افق \\
\hline$\% 20$ & 8 & أو افق إلى حد ما \\
\hline$\% 10$ & 4 & لا أو افق \\
\hline$\% 100$ & 40 & المجموع \\
\hline
\end{tabular}




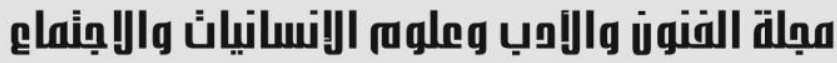

Journal of Arts, Literature, Humanities and Social Sciences www.jalhss.com

Volume (60) November 2020 العدد (60) نوفمبر 2020

حضور برنامج تدريبي ينُجع على عمل مشروع صغير

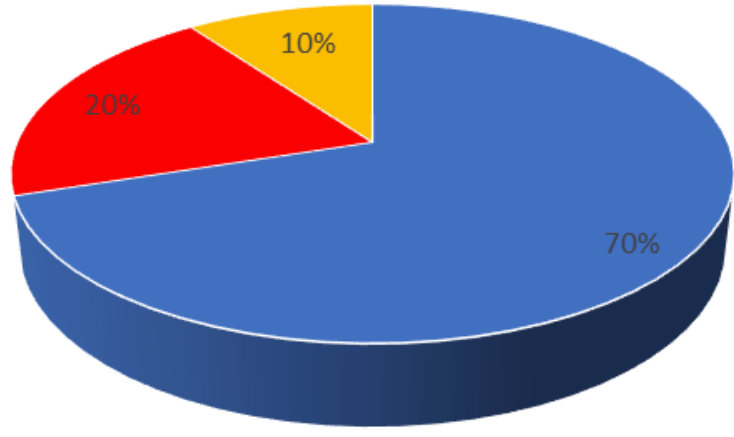

$$
\text { لا أو افقى - أو افقى الي حد ما - أو افقى - }
$$

شكل (10) يوضح هل حضور أفر اد العينة برنامج تدريبي تشجعهم على عمل مشرو ع صغير

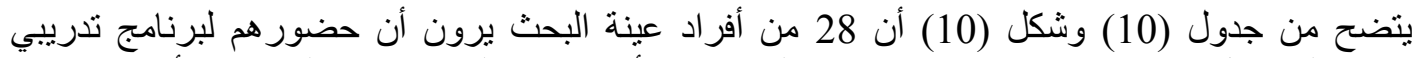

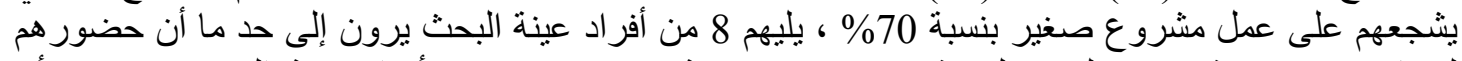

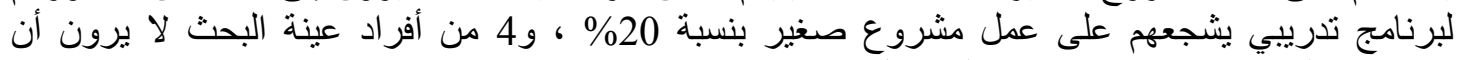

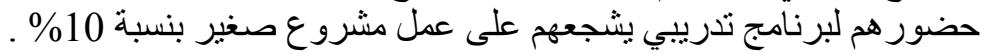

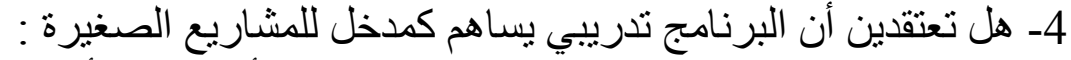
يوضح الجدول (11) و الثكل البياني رقم (11) هل يعتقد أفر ادئ العينة أن البرنـامج التدريبي يسـاهم كمدخل للمشاريع الصغيرة جدول (11) هل يعتقد أفر اد العينة أن البرنامج تدريبي يساهم كمذخل للمشاريع الصغيرة

\begin{tabular}{|c|c|c|}
\hline النسبة\%\% & 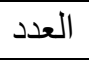 & البرنامج تدريبي يساهم كمدخل للمشاريع الصغيرة \\
\hline$\% 62.5$ & 25 & أو افق \\
\hline$\% 32.5$ & 13 & أو افق إلى حد ما \\
\hline$\% 5$ & 2 & لا أو افق \\
\hline$\% 100$ & 40 & 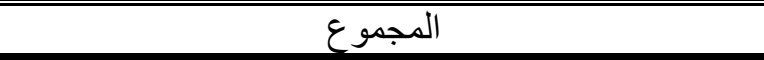 \\
\hline
\end{tabular}




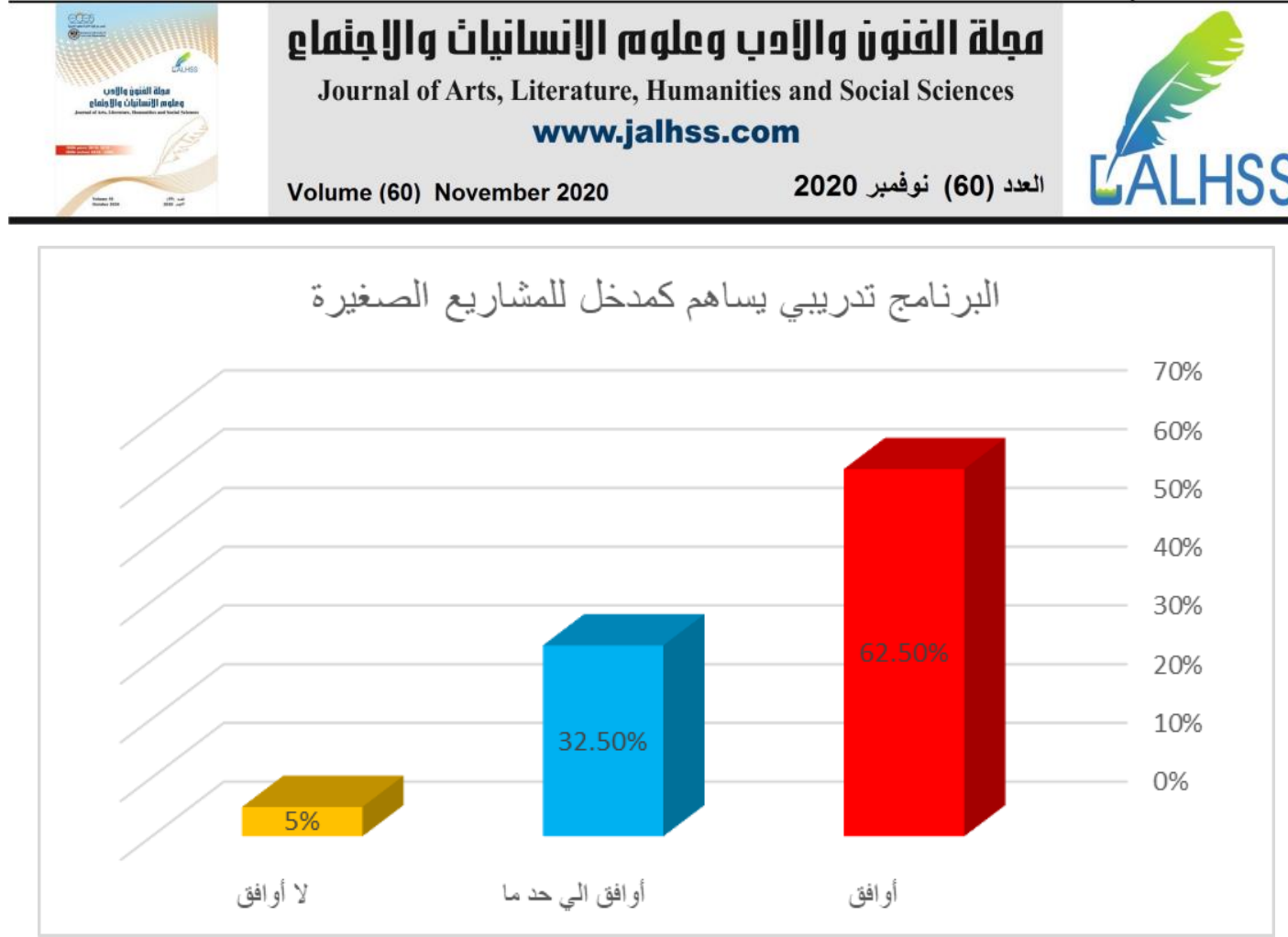

شكل (11) يوضح هل يعتقد أفر اد العينة أن البرنامج تدريبي يساهم كمدخل للمشاريع الصغيرة

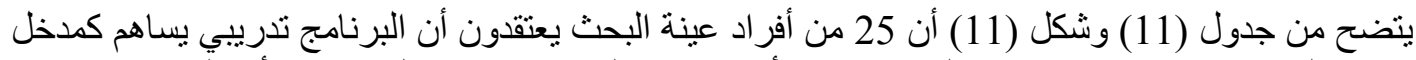

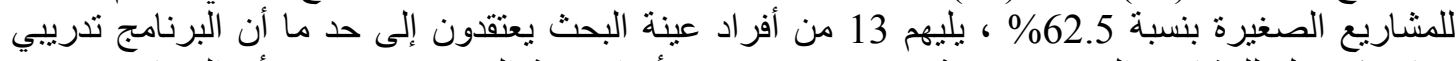
يساهم كمدخل للمشاريع الصغيرة بنسبة 32.5\% \%

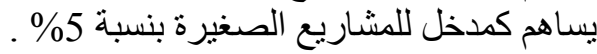

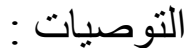

1- تبادل الخبرات المكتسبة بين المختصين في المجال و التخصصات الأخرى للتطوير ودمجها في التطبيق

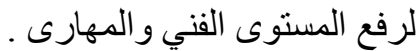

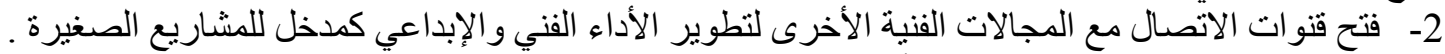

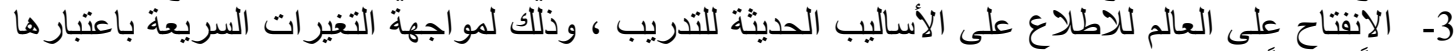

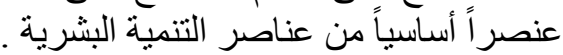
4- التأكيد على دور الجامعات لحثهم على إجر اء الأبحاث و الدراسات عن مؤسسات الدولة.

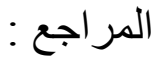

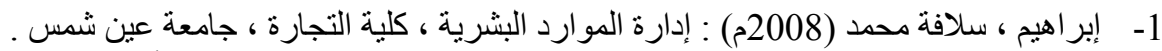

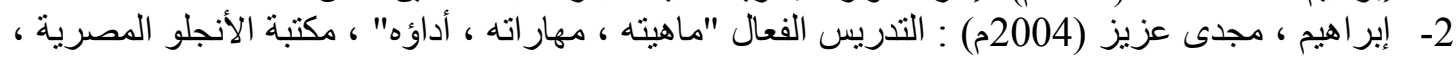

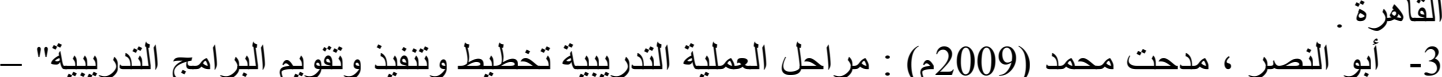

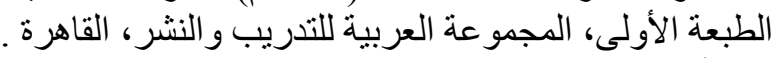

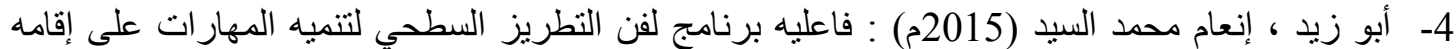

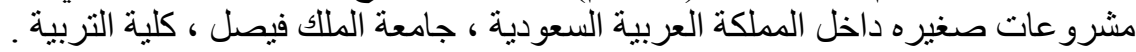

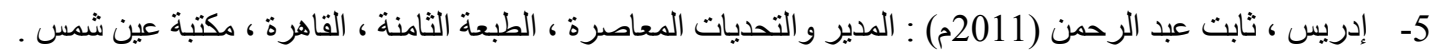

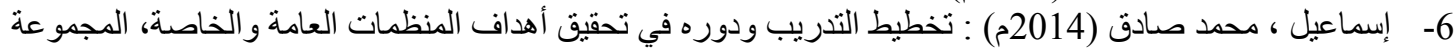
العربية للتدريب و النشر ، القاهرة . 7- الحريري ، ر افدة عمر (2014م) : اتجاهات حديثة في إدارة الموارد البشرية ، إلبازوري للنشر و التوزيع ، 8- عمان الخطيب ، أحمد (2006م) : الحقائب التنريبية ، الطبعة الأولى ، عالم الكتب الحديثة للنشر و التوزيع ، عمان 9- الدهشان ، جمال علي (2017م) : الاحتياجات التدريبية، مفهومها، أهيتها ، أساليب تحديدها، دراسات عربية في

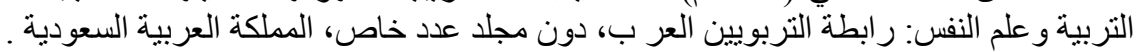




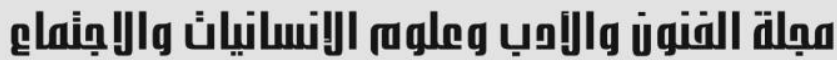

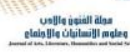

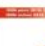

Journal of Arts, Literature, Humanities and Social Sciences

www.jalhss.com

Volume (60) November 2020

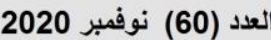

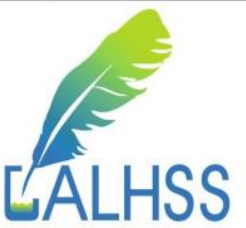

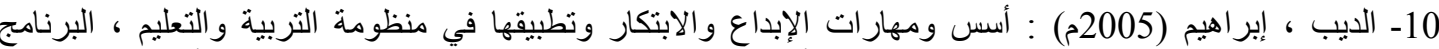
التدريبي العملي لإعداد المعلم المبدع في إعداد وتنفيذ أساليب التربية والتعليم وبناء الجيل القادم ، مؤسسة أم القرى للترجة الترجة

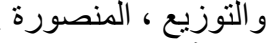

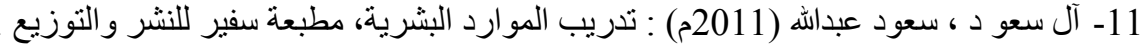

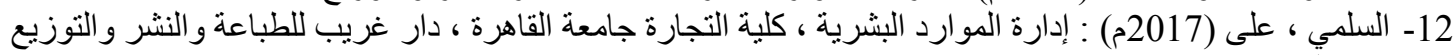

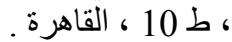

13- السيد ، أمل عبد الرحمن (2010م) : إدمارة إدارة الموارد البشرية ، كلية التجارة ، جامعة القاهرة .

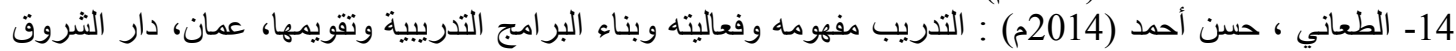

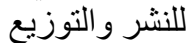

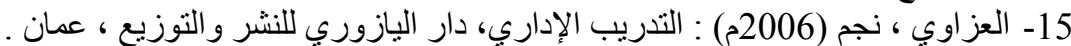

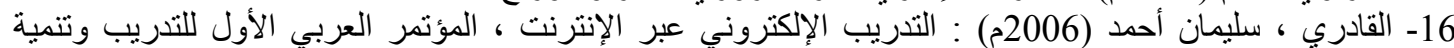

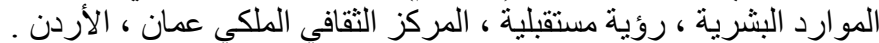

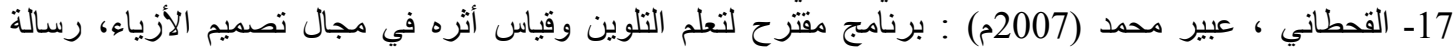
ماجستير غير منشورة ، كلية التربية ، قسم الملابس و النسيج النيان. 18- الكبيسي ، عامر خضير (2002م) : أولويات التنديب الأمني العربي "رؤية منهجية"، جامعة نايف العربية للعلوم

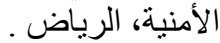

19- النسور ، زياد عبدالكريم (2017م) : الدليل التنريبي لتتمية الموارد البشرية ، دار الأكاديميون للنشر و التوزيع ، عمان

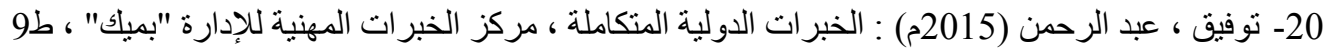

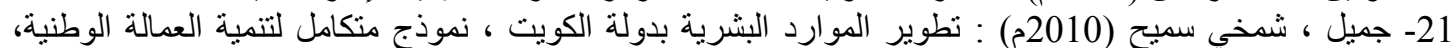

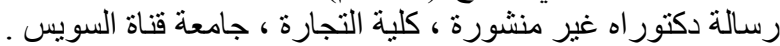

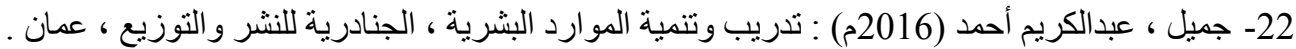

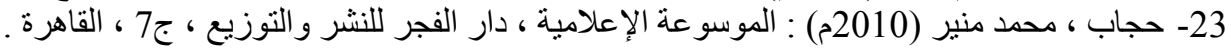

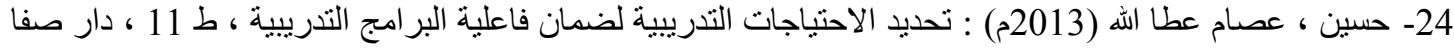

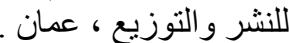
25- خليل ، خالد إبر اهيم (2016م) : فعالية البر امج التدريبية الممولة من الخارج في القطاع الصحي الحكومي ، فلسطين ، " دروزة ، أفنان نظير (2001) : و واقع التعليم المفتو ح كما بر اه كل من الطالب و المشرف الأكاديمي و الموظف الإداري

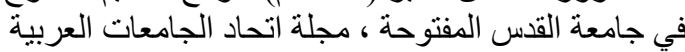
27- دياب ، عبد الفتاح (2014م) : إدارة الموارد البشرية ، عضو هيبة البئة التنديس بقسم إدارة الأعمال تجارة بني سويف جامعة القاهرة ، ورئيس المجمو عة الاستشارية العربية ، القاهرة . 28- زيتون ، حسن حسين (2013) : تصميم التذريس رؤية منظومية "سلسلة أصول التدريس" ، المجلد "4" ، عالم

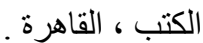

29- رشيد ، مازن فارس (2004م) : إدارة الموارد البشرية ، الأسس النظرية والتطبيقات العملية ، الرياض ، مكتبة العبيكان. 30- رضا ، أكرم (2011م) : برنامج تدريب المدربين ، دار التوزيع و النشر الإسلامية ، القاهرة .

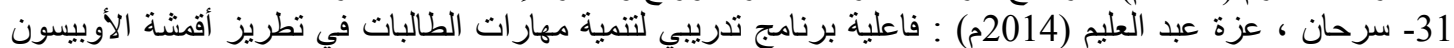

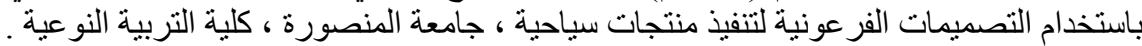
32- صالح ، عادل حرحوش ، السالم ، مؤيد سعيد (2006) : إدارة المو ارد البشرية مدخل استر اتيجي، عالم الكتب الحديث

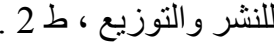

33- عبد الباقي ، صلاح الدين محمد (2011م) : إدارة الموارد البشرية من الناحية العلمية و العملية ، كلية التجارة ، جامعة

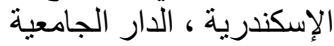
34- عبد الحكم أحمد الخزامي (2003م) : إدارة الموارد البشرية "التحديات ، التجارب ، التطلعات" ، دار الكتب العلمية

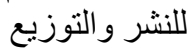
35- عبد الفتاح ، ر أفت السيد (2006م) : سيكولوجية التندريب وتتمية الموارد البشرية ، دار الفكر العربي ، القاهرة .

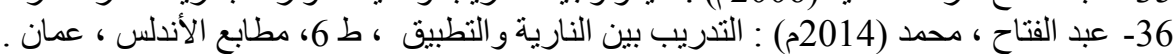

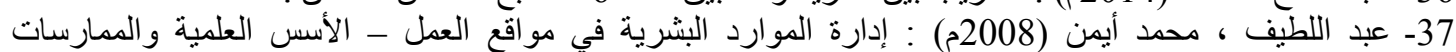

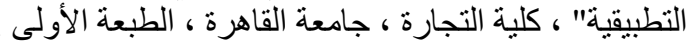

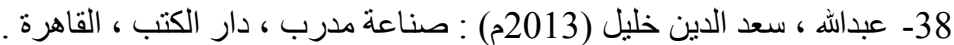

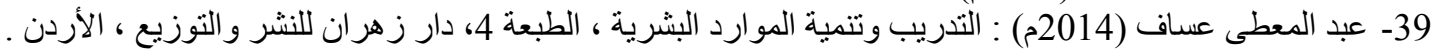




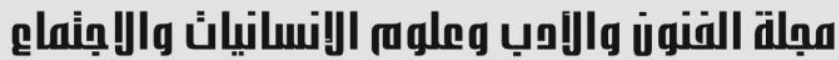

Journal of Arts, Literature, Humanities and Social Sciences www.jalhss.com

40- عبد الوهاب ، على محمد (2009م) : إدارة الموارد البشرية ، جامعة عين شمس ، القاهرة ، مصر .

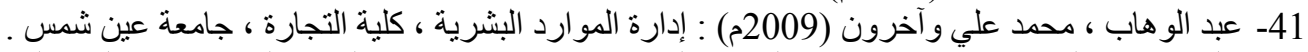

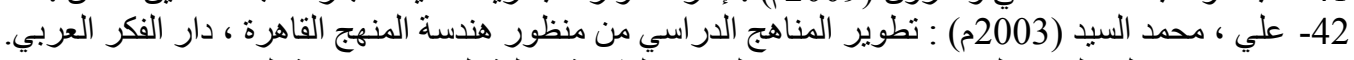

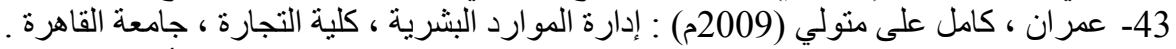

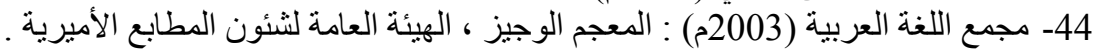

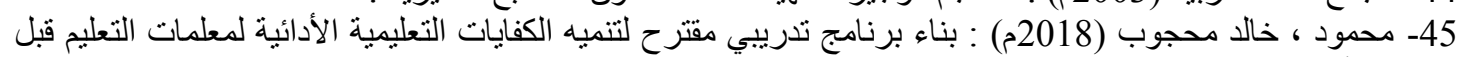

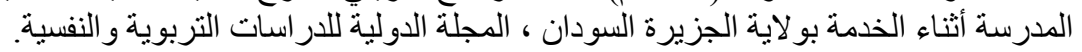
46ـ محدد عقلة (2012م) : التدريب الإداري الموجهة بالأداء ، ط 1، المنظمة العربة العربية للتنمية الإدارية ، جامعة الدول

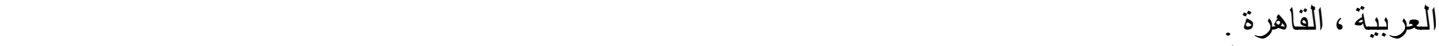
47- مصطفى ، أحمد سيد (2015م) : إدارة الموارد البشرية ، منظور القرن الحادي والعشرون ، كلية التجارة ، ط 8 ،

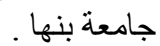

48- Combs, L., : The Design Assessment, and Implementation of A Web-Based Course, Kennesaw State University, USA, Association for the Advancement of Computing in Education, Vol. 12, No.1, 2004.

49- David Osboran: Human Resource Management, 2006, Virginia, Reston Publishing, Co.

50- Michael Armstrong: "Management Techniques", Jarir Bookstore, 2010.

51- Vass Dianna: "Setting up a training program through the application of total quality system (TQM) in the clothing and textile companies in North Carolina, 2006, USA 